\title{
Business Narrative Modelling Language (BNML) representations: A storyline view and a plot view of how interoperability is an antecedent of innovation at IP BRICK
}

\author{
Manuel Au-Yong Oliveira ${ }^{1,2}$ and Joao Jose Pinto Ferreira ${ }^{1}$ \\ ${ }^{1}$ INESC TEC (formerly INESC Porto), Faculdade de Engenharia, Universidade do Porto, Rua Dr. Roberto Frias, 378, \\ 4200-465 Porto, Portugal. \\ ${ }^{2}$ Department of Economics, Management and Industrial Engineering, University of Aveiro, Campus Universitário de \\ Santiago, 3810-193 Aveiro, Portugal.
}

Accepted 2 December, 2011

\begin{abstract}
The relationship between interoperability and innovation is very hard to prove and more empirical studies seem to be needed to this end. We performed an in-depth case study at an innovative Portuguese software firm which has achieved steady growth, international brand recognition and consistent annual profits, despite the much publicized economic crisis in Portugal. IP BRICK is interesting as it differs from the survivalist entrepreneurial endeavours which tend to be the norm in Portugal. We indeed conclude that having an interoperability capability is central and an antecedent to innovation. Furthermore, a dynamic organizational innovation culture is instrumental and Information and Communication Technology (ICT) is seen to be an enabler in the process. Using digital knowledge management tools as a basis for innovation and having a company-wide profit-sharing scheme based on seniority, but also on merit, encourage a knowledge-sharing corporate culture. This is seen to be especially important in Portugal where there is no religious diversity, a characteristic of a dogmatic culture with a low creative orientation and an absence of a performance orientation. Our research has also used the Business Narrative Modelling Language (BNML) - a research tool which made the research effort more agile and dynamic when compared to more traditional research methods.
\end{abstract}

Key words: Interoperability, innovation, Information and Communication Technology (ICT), case study, Business Narrative Modelling Language (BNML).

\section{INTRODUCTION}

The importance of innovation has been emphasized in the literature. Economic growth improves quality of life as incomes tend to rise with increases in gross domestic product (GDP) (Porter et al., 2004) and technological innovation in particular leads to increased growth (Schwab, 2010). Furthermore, knowledge management, which includes discovering knowledge, generating

${ }^{\star}$ Corresponding author. E-mail: manueloliv@gmail.com. Tel: +35122618 8258 . knowledge and sharing knowledge (Jashapara, 2004) "is the most significant input to innovation, one of the preconditions for global organisations. This is one of the only ways that organisations can keep up to date with developments in technology, processes, customer demands, social changes and competitor changes" (du Plessis, 2008). Thus, a knowledge-sharing and dynamic organizational innovation culture must be promoted. The case study discussed herein benefits from - and seeks to contribute to - the organizational innovation culture and knowledge sharing literatures and is about a company which leverages knowledge (of employees, of customers) 
to create innovative products. Rather than having a "warehouse" of knowledge (involving simply storing knowledge for later use) at IP BRICK we shall see how they leverage "the 'learning' model where the creation and use of knowledge is seen as the outcome of an ongoing interaction between subject and world" (Kimble and Bourdon, 2008). We see this ongoing interaction as occurring due to the existence of an interoperability capability, defined as "the ability of a system or an organization to work seamless[ly] with other systems or organization[s], without any special effort" (Mertins et al., 2008), very evident in our case study findings. Cooperation and collaboration and information flows at IP BRICK lead to knowledge-creation and knowledgesharing and ultimately to innovation. As early as 1990, Porter - The cluster school - drew from Marshallian externalities "to study how geographical proximities between firms and its suppliers, customers, and competitors can lead to more innovative products" (Tzeng, 2009). We are not only interested in this aforementioned proximity, we are also interested in how information and communication technology (ICT) can overcome physical distance to promote information and knowledge exchanges and thus lead to innovation. We are witnessing "a new wave of innovation processes fuelled by [the] "wisdom of the crowd" and powered by a new generation of enabling technologies" (Li, 2008); not only the nature of innovation is changing, the context of interoperability is changing also.

Portugal has dropped since the 2005 - 2006 global competitiveness index (GCl) ranking from 22 nd place to 46th place only five years later $(2010$ - $2011 \mathrm{GCl}$ ranking). This has to do with decreases in a set of measures including technological readiness, business sophistication and innovation. As the company discussed herein has managed to counteract the tendency to decrease its competitiveness and has managed to grow and have profits even amidst a major crisis we believe that the lessons learned may be useful to other similar companies operating in Portugal as well as internationally.

Gasser and Palfrey (2007) state that "One of the reasons why we tend to like interoperability is we believe it leads to innovation". However, "the relationship between interoperability and innovation, while it likely exists in most cases, is extremely hard to prove" (Gasser and Palfrey, 2007). So, enterprise interoperability is "the ability of an enterprise to interact with other organizations, to exchange information and to use the information that has been exchanged. It should be noted that interoperability is not only a property of ICT systems, but also concerns the business processes and the business context of an enterprise" (Li et al., 2006). Being able to seamlessly interoperate with others is a determinant of organizational competitiveness and while ICT is increasingly seen as being an essential tool leading to competitive advantage (Porter, 1980) "enterprise interoperability has become a strategic necessity in all industries" (Li et al., 2006).

Following a literature review, which involved both systematic searches of the Science Direct data base as well as non-systematic searches of various sources, in which we identify a gap in the literature which we seek to fill - related to the relationship between interoperability, innovation and, also, ICT - we then move on to discussing the objectives and methodology for our research paper and then present the case study we have carried out to achieve our research objectives. We use the Business Narrative Modelling Language (BNML), a novel research method (Oliveira and Ferreira, 2011a), to expose the relationship between interoperability, innovation and ICT. BNML involves visual representations but also resorts to the narrative, thus combining two strategies for theorizing from process data, which is seen to be more advisable (Langley, 1999). Graphviz software also provided an additional basis which we used to achieve our research objectives: Interoperability is seen to be an antecedent of innovation, enabled by ICT. We also discuss our case study findings in view of the literature and finalize with suggestions for future research.

\section{LITERATURE REVIEW}

The literature review that follows commenced according to Corbin and Strauss's (2008) statement that "there is no need to review all of the literature in the field beforehand, as is frequently done by researchers using quantitative research approaches. It is impossible to know prior to the investigation what salient problems or what relevant concepts will be derived from this set of data. There is always something new to discover. If everything about a topic is known beforehand, there is no need for a qualitative study. Also, the researcher does not want to be so steeped in the literature that he or she is constrained and even stifled by it." Thus, the literature reviewed has been "a source for making comparisons... to stimulate questions during the analysis... to confirm findings" (Corbin and Strauss, 2008) as well as to illustrate where the literature "only partially explains a phenomenon" (Corbin and Strauss, 2008).

We performed systematic searches in a major data base - science direct - as well as other non-systematic searches - in order to reach "a firm foundation for advancing knowledge" (Webster and Watson, 2002). As described below, we shall see that, in particular, the relationship between interoperability and innovation has not been a focus of much research, prior to our study.

\section{Innovation}

A main focus of management research is to help 
organizations successfully achieve sustainable growth in this context, consistently contributing to the increase of innovation is one way sustainable growth can be achieved (Christensen and Raynor, 2003). Indeed companies are increasingly under pressure to provide something new and valuable to consumer as well as to business markets (Johansson, 2007). One view in particular portrays companies operating in free-market economies as being similar to organic systems found in nature: a) natural selection will dictate that only the fittest will survive; b) subsequent generations will have to operate according to higher standards; c) enterprises must continually evolve to meet the unending challenge of providing new competitive advantages not yet neutralized by the competition (Moore, 2006) - the challenge is to "innovate or disappear" (Moreira, 2011).

Earlier work on competitive strategy emphasized how strategic advantage could be attained either by: a) industry-wide differentiation; b) overall cost leadership; or by c) achieving differentiation or lower costs while focusing on a particular segment only (Porter, 1980). More recent work has however pointed to the need for having simultaneously both differentiation and low cost products and services in order to create uncontested space in markets where the competition is not relevant (Kim and Mauborgne, 2005; van Assen et al., 2009). Differentiation or low costs can be achieved via a number of innovations, up to fourteen in total, to which all companies are exposed: disruptive innovation, application innovation, product innovation, platform innovation, line-extension innovation, enhancement innovation, marketing innovation, experiential innovation, value-engineering innovation, integration innovation, process innovation, value-migration innovation, organic innovation and acquisition innovation (Moore, 2006).

Despite the variety and importance of innovation to companies operating in today's marketplaces, most managers are dissatisfied with the way innovation is managed in their organizations (Tidd et al., 2005). In effect, great variations in innovation performance can be found even between companies operating in the same sector, variations which lead to different market shares, profitability levels, and growth and market caps (Tidd et al., 2005). Innovation in organizations will depend on a number of factors. The organizational culture - "The accumulated shared learning of a given group, covering behavioural, emotional, and cognitive elements of the group members' total psychological functioning" (Schein, 1992: 10) - is pointed out as one of those factors by a number of authors (Schein, 1992; von Hippel et al., 1999; Hargadon and Sutton, 2000; Govindarajan and Trimble, 2005; Kelley and Littman, 2006; Morgan and Liker, 2006; Johansson, 2007).

In the review of contemporary innovation literature by Tzeng (2009) three main schools of innovation are put forth: economic perspective, social perspective and cultural perspective (or culture school).
The economic perspective views innovation as an institutionalized capability, linked to routines. The social perspective focuses on "authentic voices". The culture school, which interests us most, sees innovation as being a deep craft (Arthur, 2001, as quoted by Tzeng, 2009) of "affective identification" where shared beliefs and practices, taking the form of a collective memory, are the basis rather than technique or material motivation. A personal commitment of the revolutionary type (Berger and Luckman, 1967, as quoted by Tzeng, 2009), where faith is central (Hounshell, 1992, as quoted by Tzeng, 2009), is a necessary pre-requisite. Innovation is thus seen as a "calling" involving heart and soul (Weber, 1976, as quoted by Tzeng, 2009) and intrinsic rather than extrinsic motivation (Stern, 2004, as quoted by Tzeng, 2009). Being creative involves loving the process of innovation (Amabile, 1997) and having a successful innovative enterprise will depend on gathering such people together and organizing their efforts; while recognizing at the same time that innovation tends to be unplanned, accidental and unintentional (Rosenberg, 1990). This brings us to the next concept central to our study - interoperability - as, for example, interoperability problems arise "related to simultaneous business and product development" (Knothe and Jochem, 2009).

\section{Interoperability and innovation}

Interoperability is related to standards which "provide a way of sharing ideas" (Egyedi and Sherif, 2010). Interoperability is also concerned "with the ability of diverse systems and organizations to work together" (Peat, 2009). Interoperability can be defined as "the ability of a system or an organization to work seamless[ly] with other systems or organization[s] without any special effort" (Mertins et al., 2008) or further still as "the ability of people, organizations, and systems to efficiently and effectively exchange and use information" (Tsilas, 2007). We are interested in particular in interoperability as pertaining to people and organizations able to operate in conjunction (together) to produce innovation, whether it be product innovation (changes in products/services), process innovation (changes in the creation and delivery process), position innovation (product/service introduction/context changes) or paradigm innovation (changes in the mental models underpinning the organization) - which are "the '4Ps' of innovation" (Tidd et al., 2005). Gasser and Palfrey (2007) state that "One of the reasons why we tend to like interoperability is that, we believe it leads to innovation". However, they continue, "the relationship between interoperability and innovation, while it likely exists in most cases, is extremely hard to prove".

A systematic search in the Science Direct data base, on the 17th of February 2011, revealed the following 
Table 1. Search form №1.

\begin{tabular}{ll}
\hline Content & Explanation \\
\hline Objective of the search & $\begin{array}{l}\text { Reveal whether research into the area of interoperability has been undertaken by a } \\
\text { significant number of researchers; and reveal, also, how recent the interest is in this topic } \\
\text { Data base }\end{array}$ \\
$\begin{array}{ll}\text { Science direct, as this is a major academic data base } \\
\text { Date of search }\end{array}$ & $\begin{array}{l}\text { Articles published in journals; in the period } 1823 \text { to 2010; in the social sciences area; } \\
\text { containing "interoperability" in the title }\end{array}$ \\
Inclusion criteria & 21 \\
Total number of articles found & 1998 \\
\hline
\end{tabular}

Table 2. Search form №2.

\begin{tabular}{ll}
\hline Content & Explanation \\
\hline Objective of the search & $\begin{array}{l}\text { Reveal whether research into the area of interoperability and innovation has been } \\
\text { undertaken by a significant number of researchers; and reveal, also, how recent the } \\
\text { interest is in this topic }\end{array}$ \\
$\begin{array}{ll}\text { Data base } & \text { Science direct, as this is a major academic data base } \\
\text { Date of search } & 21-02-2011 \\
\text { Inclusion criteria } & \begin{array}{l}\text { All sources; with "interoperability" and "innovation" in title, abstract and key words; area of } \\
\text { business, management and accounting; all years }\end{array} \\
\text { Total number of articles found } & 2 \\
\text { First article dating from } & 2006 \\
\text { References found } & \text { Hyvättinen (2006) and Chu et al. (2009) }\end{array}$ \\
\hline
\end{tabular}

search form (Saur-Amaral, 2010) in Table 1. We can see that the interest in interoperability is relatively recent, dating from 1998-only 21 journal articles were found with "interoperability" in their title.

Another systematic search in the science direct data base, performed on $21^{\text {st }}$ of February 2011, revealed the following search form (Saur-Amaral, 2010) in Table 2. We can see that when narrowing the search down to "interoperability" and "innovation" in the title, abstract and keywords, in the area of business, management and accounting that only two articles were found; meaning that more research into this topic is needed.

The two references resulting from the second systematic search of the Science Direct data base were
Hyvättinen (2006) and Chu et al. (2009). Hyvättinen (2006) speaks of interoperability problems which "suggest a need for systematic efforts to ensure the actual interoperability of components in technology programmes based on an interface standard" (Hyvättinen, 2006). The focus of Hyvättinen (2006) is thus different from our research, our research being more interested in the concept of agility, for example. Agility is connected to interoperability in so far as the "agile enterprise", as related to innovation, is able "to generate many solutions to a problem" (Izza et al., 2008). Chu et al.'s (2009) research focus, on the other hand, is not entirely different from ours as the focus is on effective content management to "achieve the goal and value of 
knowledge management". Knowledge is seen by Chu et al. (2009) as being "the most important asset of individuals as well as of organizations", determining enterprise competitiveness (Chu et al., 2009). Another more recent study by Bhalla (2011) similarly speaks of new platforms of collaboration and co-creation - in essence of knowledge sharing - which lead to innovation; this, much like Chu et al. (2009), also interests us. We thus can see that research into the theme interoperability is recent and lacking - especially relating the term to innovation - with innovation as an output, resulting from the firm's interoperability capability. Li et al. (2006) also affirm that "interoperability is a relatively recent term"; and Hahn (2004) states that "research in interoperability is weakly structured. Some approaches exist but are partial and usually IT-oriented."

In effect, the term interoperability has been used in various fields. Forment et al. (2009) state that interoperability is a "must have feature" for learning management systems (LMS) to enable "disruptive learning innovation practices" - ICT here empowers learning innovation. On the other hand, innovation and interoperability are key future E-Government themes, stated Raus et al. (2010). Further still, Martin and Eisenhardt (2010) speak of interoperability between products, such as between Disney theme parks and films (which share characters) and between Apple's integrated products (computer, iTunes, iPod, iPhone [and iPad]). lorio (2009) relates interoperability to an interoperable communications system between police, fire and emergency management in Tampa, Florida (thus being a "regional cooperative effort"). Egyedi and Sherif (2010) discuss next-generation Ethernet Networks and emphasize the need to develop state-of-the-art standards while combining standardization with innovation interoperability is called into question when (inevitably) standards change, leading in turn to increased transaction costs. Silverstein and Schomberg (2007) highlight interoperability in the design of a new meteringsystem architecture for the electric industry (public utilities). Dini et al. (2008) relate interoperability to digital ecosystems. Small and medium sized enterprises (SMEs), on the other hand, also need to create value and this is often achieved in their case by specializing in niche activities but they also will "have to combine forces to compete jointly in the market... [and] seamlessly interoperate with others" (Li et al., 2006). Indeed enterprise interoperability is ever more a strategic necessity in all industries (Li et al., 2006).

Interoperability appears as a need, indeed "enterprise interoperability is an area where research can lead to outstanding results in terms of innovation, leading to economic growth and employment." (Li et al., 2006); enterprise interoperability types including: communication, coordination, cooperation, collaboration and channel ( $\mathrm{Li}$ et al., 2008). The need to effectively exchange and use information (to interoperate) increases as one moves from coordination to cooperation to collaboration, suggests Pollard (2005). This is because the desired outcome goes simply from efficiency in meeting objectives (coordination) to efficiency in meeting objectives but at the same time saving time and cost (cooperation); and yet still further to efficiency in meeting objectives while saving time and cost, but where innovative breakthrough results also want to be accomplished (collaboration). Especially in the latter case effective use of ICT can lower the need for the physical co-location of the actors involved, providing a channel for communication. A team collaborating is an interdependent group thus interoperability is key.

Interoperability has been linked to Allee's value [innovation] networks which imply the need for interoperability. "Enterprises need to concentrate on value innovation and producing more of not the same (with higher margins). To this end enterprises operate increasingly in dynamic value networks" (Li et al., 2008: 2). Therefore, interoperability needs to be geared towards making use of and indeed increasing "creativity, collaboration and change in more dynamic networks to release its full potential as an instrument for value creation" (Li et al., 2008). Li et al. (2008) further state that in the search for increased profitability, interoperability should be "a means for developing blue ocean strategies (Kim and Mauborgne, 2005), by creating value innovation for customers" which in turn means "simultaneously pursu[ing] differentiation and low cost... value innovation, that is, introducing radical innovations in the products, services, processes, etc., that are genuinely valued by customers" (Li et al., 2008). Creating new market territory where the existing competition is not relevant will result (Kim and Mauborgne, 2005). However, the process involved and by which this is achieved, leveraging interoperability, is not described; a gap in the literature which we intend to overcome with our detailed case study. A framework for enterprise interoperability (FEI) is provided by ISO (2009). This framework is for describing and representing concerns (there are 4 concerns business, process, services and data), barriers (there are 3 barriers - conceptual, technological and organizational) and approaches to enabling enterprise interoperability (ISO, 2009). The method prescribed by ISO (2009) makes the quantification of existing capabilities possible (AS-IS situation), while at the same time identifying those missing capabilities which need to be improved upon in order to achieve higher interoperability levels (TO-BE situation).

\section{A relationship between interoperability, innovation and ICT}

We intend to expose in our paper how ICT enables interoperability which leads to innovation. Some links 


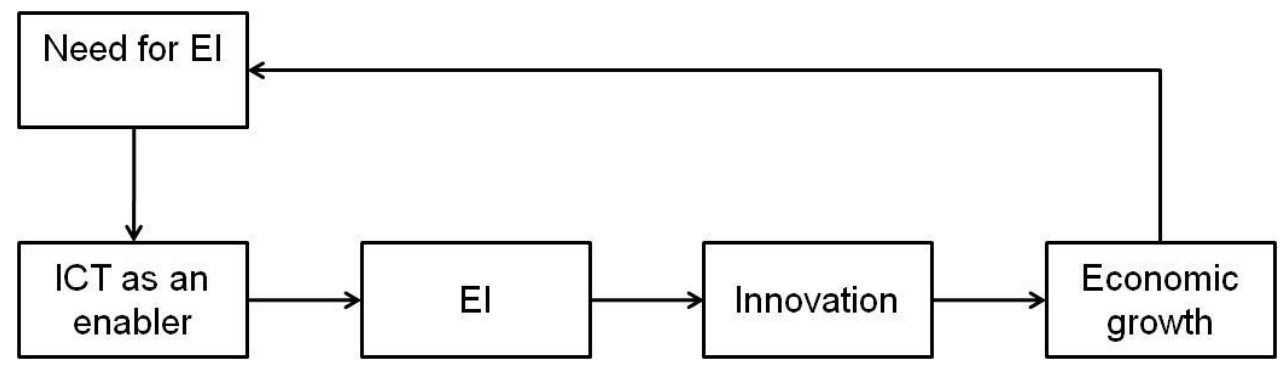

Figure 1. The relationship between interoperability, innovation and ICT (a suggestion by the authors based on the literature).

exist in the literature between interoperability, innovation and ICT - ICT having been "entwined with major changes in society since the invention of electrical telegraphy in the 1830s" (Mansell et al., 2007). ICT is seen as being "the innovation engine that will continue to drive growth and value for the next ten years" (Reding, 2008). An objective of our research is to prove that a relationship between enterprise interoperability (EI), innovation and ICT exists. We believe that the relationship is a direct one, as Figure 1 illustrates. Several references in the literature provide support for the relationship suggested in Figure 1:

1) Technologies are potentially seen as enablers rather than as determinants of particular outcomes (Mansell et al., 2007);

2) ICT can be seen to be the innovation engine" (Reding, 2008);

3) Enterprise interoperability is expected to have an ever increasing contribution to the impact of ICT on economic growth. (Li et al., 2008);

4) Enterprise interoperability will likely create value for the economy as well as society at large (Li et al., 2008).

5) According to Serrano and Fischer (2007) interoperability is related to a new paradigm - that of ubiquity and its contribution to collaborative innovation interoperability will evolve in future as a new form of intelligence and the influence of technology is undeniable.

6) Similarly, Hahn (2004) states that interoperability is essential for innovation to occur as it allows for seamless cooperation as well as optimized processes; in turn this will be dependent on new technologies, both within, as well as between enterprises.

7) Furthermore, networked enterprises are a growing phenomenon (lansiti and Levien, 2004) and are ever more supported by ICT (Li et al., 2006), ICT being a critical infrastructure underpinning both the economy and society (Li, 2008).

We are interested in facilitating co-creation. Indeed, how interoperability, connected to a new concept of enterprise systems (Li, 2008) drives open innovation of enterprises (Chesbrough, 2007) is a very current topic considered to be a key factor by the European Commission ( $\mathrm{Li}, 2008)$.

Finally, the importance of innovation (von Hippel et al., 1999; Lilien et al., 2002; Cash et al., 2008; Kotler and Keller, 2009) and the necessary collaboration (Dyer and Nobeoka, 2000; Kogut, 2000; MacCormack and Herman, 2004; Camarinha-Matos and Afsarmanesh, 2005a, b; 2007, 2008; Camarinha-Matos, 2008a, b; Pisano and Verganti, 2008) in order to achieve this end cannot be underestimated. A growing body of literature is proof of this and we see it as leading up to the need for interoperability. Furthermore, the role of ICT (digital connectivity) is seen as being fundamental, indeed strategic in the way it makes possible improved information processing routines, which is the basis for increased innovation (Pavlou, 2004; Rabelo, 2008; Rabelo et al., 2008; Cash et al., 2008; Bonabeau, 2009). ICT is an innovation engine (Reding, 2008) and "EI [enterprise interoperability] may have an increasing contribution to the ICT impact" ( $\mathrm{Li}$ et al., 2008). Interoperability is believed to be an antecedent of organizational innovativeness. Innovativeness is defined here as the ability of organizations to generate new product (or service) sales.

\section{A contribution to the literature}

There are a number of diverse studies mainly linking interoperability, innovation and technology. However, more empirical studies are seen to be needed. Hahn (2004), Li et al. (2006) (European Commission), Li et al. (2008) (European Commission) and Egyedi and Sherif (2010) are examples of studies linking interoperability, innovation and technology but which did not do any apparent empirical work. Qualitative data gathering (using interviews), our method in this study, has been used before in interoperability research such as by Martin and Eisenhardt (2010) and by Raus et al. (2010). Martin and Eisenhardt's (2010) research differs from ours as they investigated cross-business-unit collaboration and 
large firm value creation. Our study focuses on interoperability within an SME as well as between the firm and partners (customers) and which leads to innovation. Raus et al. (2010), in turn, evaluate information technology innovations in a business-to-government context quite distinct from our context. They performed a single case study about establishing an interoperable platform to connect a multitude of suppliers. We thus see our study as contributing to the existent literature on interoperability and innovation, and in particular as it focuses on a Portuguese company. Portuguese companies have not been a consistent focus in international publications. Some publications have discussed Portuguese entrepreneurial endeavours namely Baptista et al. (2008, p.56) who state that in Portugal there is a "relatively high prevalence of subsistence, or necessity-based, entrepreneurial activity... associated with high mortality and low growth rates for new firms, thus leading to relatively small effects of new business formation on employment growth." IP BRICK is an example of a Portuguese start-up which has countered the tendency mentioned by Baptista et al. (2008) and thus merits attention.

\section{Objectives}

The novel modelling framework BNML (Oliveira and Ferreira, 2010a, b, c, 2011a, forthcoming) uses storylines, the narrative, game patterns and ontologies to reduce the time necessary to perform qualitative research analyses, while increasing at the same time the consistency across qualitative case studies.

A map can be defined as "a visual representation that... names the most important entities that exist within that domain, and simultaneously places them within two or more relationships... and encourages mentally moving among entities... [becoming] a helpful record of emerging knowledge" (Huff and Jenkins, 2002). While BNML, following exploratory research, apparently achieves this see, for example, the projects which we have been involved in - Almeida (2010) who used BNML in her Master's dissertation to model the business narrative of a strategic consultancy process; and Krause (2011) who, in his Master's dissertation, applied BNML to classify conceptual patterns - further in-depth research is necessary to confirm the validity and ease of use of BNML.

Thus, the following research question which we aim to address is as follows: Does BNML contribute to qualitative research by supplying a modelling framework which greatly simplifies the qualitative analysis process, while providing at the same time for a more consistent approach and enabling comparison across cases?

It is also our objective with this study to apply BNML to a specific research problem and as "innovation nowadays is at the top of the strategic agenda of corporations" (Tzeng, 2009) we set out to analyse how different organizations go about achieving their goal of bringing innovative products (and / or services) to the marketplace, while leveraging interoperability between systems enabled by ICT. Our research objective then is also to test the BNML (Oliveira and Ferreira, 2011a), which we have developed, and in particular to use it to determine the relationship between interoperability, innovation and ICT.

\section{METHODOLOGY}

It is generally accepted that there are two divergent paths in knowledge development (Scapens, 2007): one involves the formulation of a tentative theory followed by controlled situational events and empirical deductions (using statistical methods and quantification / measurement procedures to reflect their perspective of knowledge), and the other, less popular, involves natural but uncontrollable observations while working towards a set of inductive principles (following the identification of a gap in the literature researchers admit to putting the literature aside to then inductively derive theory from the phenomenon - theory will emerge, as Elharidy et al. (2008) propose; Weerawardena and Mort (2006) go as far as stating that "seven emergent themes of the in-depth case study interviews" are presented).

Ghauri and Gronhaug (2005) agree and state that researchers have to opt between the use of a qualitative or a quantitative method, though the difference involves not the quality of the end result but the procedure. Admittedly there is some discussion in the literature as to which method is more "scientific". Quantitative methods, being more structured, are seen to be better by the majority of researchers in business studies. They however hold that using quantitative methods or techniques is not "better"; rather each research project will have suitable methods and techniques depending on the research problem.

According to Corbin and Strauss (2008), quality in qualitative research is something that we recognize when we see it, suggesting that perhaps qualitative research is more of an art than a science. Certainly, qualitative research should be carried out by skilled researchers whose methodology is transparent.

Qualitative research explores and rationalizes while at the same time using intuitive abstraction often based upon the shrewd sense and past experience of the researcher - the emphasis is on interpretation and understanding, in natural settings and with an "insider view", rather than on testing and verifying (and thus, using an "outsider view" which is result oriented) (Ghauri and Gronhaug, 2005).

When we want to understand a little-known phenomena, such as interoperability and its relation to innovation, qualitative research, which can provide intricate details for example concerning human behaviour, is preferable (Ghauri and Gronhaug, 2005) and indeed quite suitable for the study of individuals and organizations (Remenyi et al., 1998). It is becoming increasingly accepted among management scholars that people and their behaviour are best researched using phenomenology or the non-positivistic approach (Remenyi et al., 1998).

In performing this research, we aim to provide for an easier application of the qualitative research methodology by using our BNML. Qualitative research is seen to be inferior to quantitative research (Mason, 2002) and Yin (2003) warns that this is due to a stereotype existing against case studies in particular as they are seen to lack an objective and rigourous stance. This objectivity and 
rigour is added by our modelling tool BNML which is based on a pre-existing enterprise ontology (Uschold et al., 1998) and predefined business patterns (Bjork and Holopainen, 2005).

Thus, we aim to offer structure and objectivity to a task which other means (such as software packages) have also sought to provide in the past. The researcher will still perform (now less) exhaustive coding whereby instances will be assigned to a category. However, what will differ is the development of the coding frame which will already exist in the form of game patterns (Bjork and Holopainen, 2005) and the enterprise ontology (Uschold et al., 1998). Furthermore, we develop Allee's (2000a, b, 2002, 2008) value network analysis further by adding a time frame to the organizational narrative while maintaining asset denominations already presented in the literature - such as a sense of community, technical know-how and customer relationships (Allee, 2008).

Doumeingts and Chen (2003) (as quoted in Hahn, 2004) have stated that "enterprise modelling and ontologies should enforce the conceptual basis of interoperability research". (Hahn, 2004). This is an objective of our research, to use enterprise modelling and ontologies [present in our novel modelling language - BNML] to build on the current concept of interoperability. Ontologies, "a model of the World using meaning-based concept representations" (Oliveira and Ferreira, 2010a), are used "mainly to cover the semantic aspects of interoperability" (Hahn, 2004).

Our objective is to perform inductive theory building using a case study. The persuasive power a single case may have has been mentioned in the literature (Siggelkow, 2007) and classic scholars and authors of highly regarded papers have used the case study method (Eisenhardt and Graebner, 2007). We believe that we have found the "talking pig" that Siggelkow (2007) speaks of (that is, our case IP BRICK, a unique technology company immune to the successive crises in the Portuguese economy) and which may originate (we hope) some excitement. We have gained access to and will be reporting on real-life experiences, benefitting both academia and practice, and Dubé and Paré (2003) do state that this will add respect and interest to our study. Furthermore, "indepth case investigations open the way to new ideas and new lines of reasoning" (Dubé and Paré, 2003).

Qualitative research, namely involving interviews during primary data collection have been used in major research efforts connected to interoperability and innovation (Martin and Eisenhardt, 2010; Raus et al., 2010).

We conducted five in-depth, semi-structured interviews using an interview script, and also had two important meetings with the CEO of IP BRICK to position and clarify the research objectives. Unstructured interviews play an important role as a research tool (Bryman, 1989), where the aim is 'to elicit respondents' ways of thinking about the issues" while "minimizing the degree to which they are constrained" (Bryman, 1989). We did elicit ways of thinking of respondents, who were allowed to stray from our main subject to talk about areas which they deemed interesting and relevant - but in all of the interviews each of the questions in the interview script were satisfactorily answered. Other research tools included several company visits to observe IP BRICK functioning, an analysis of company documents and company-related media releases, the exchange of e-mails with interviewees to clarify interview issues, all of these having contributed to an effort of triangulation in order to elicit accurate and meaningful data.

\section{Usefulness and validity of the proposed study}

Portugal is our home country and so this research is aimed at contributing in a small way to increasing essential knowledge which may lead to improved quality of life here. Portugal, whilst included in an exclusive group of $\mathbf{2 8}$ advanced economies worldwide, is a peripheral European economy which is having difficulty in converging with the European Union EU-27 GDP per capita average, currently standing at roughly two-thirds of this figure (Mateus, 2006). Portugal is described as a less-favoured economy in the European context by Moreira et al. (2007) and also by Moreira et al. (2008). In relation to industrialised countries in general, Portugal has not only a technological but also a human capital deficit, with some of the poorest education indicators in Europe and in the developed World (Teixeira and TavaresLehmann, 2007). Portuguese culture is not considered to be innovation facilitating (Javidan, 2004), particularly true in the case of open innovation (Lopes and Teixeira, 2009). What can we do to move forward, away from these poor indicators?

We intend to capture, using a qualitative methodology, the stories that participants author in their work environment to provide an identity and sense to their working lives. In the midst of a turbulent environment, where interoperability, innovation, collaboration and ICT are central, qualitative methodologies are seen to be more appropriate in the case of managerial and organizational issues, "hence, an increasing interest in the application of qualitative research methods" (Myers, 1997). Such studies, which may bring to the fore rich detailed descriptions for example of how collective mind is achieved, are lacking in the literature (Hage, 1999; Pavlou, 2004; Camarinha-Matos, 2008b).

We intend to model the narratives, which are "an appropriate interpretive lens for understanding organizations" (Brown and Currie, 2003; Brown, 2006) using patterns provided by Bjork and Holopainen (2005), thus providing another important and novel perspective on Allee's (2000a, b, 2008) work on value networks and the creation of value.

The case studied - IP BRICK - adds to the interest of the project in so far as it has been carefully chosen to represent relevant issues in various highly competitive and turbulent environments today.

\section{Empirical study}

This article presents the results of a case study. This research strategy is seen to be appropriate for our inquiry into the relationship between interoperability, innovation and ICT as our research question focuses on a contemporary event (Yin, 2003). The data was collected during company visits, meetings, interviews, telephone and e-mail exchanges, as well as resorting to corporate website and document analyses and articles in the popular press about the companies. Digital corporate product and brand advertising videos present on www.youtube.com were also a source of information. "The use of mixed or multiple methods in case study research usually contributes to increasing accuracy and complexity/coverage in a study" (Woodside, 2010).

During the processes of data gathering, representation and analysis the research team also resorted to a novel qualitative research methodology developed by the research team and called the BNML (Oliveira and Ferreira, 2010a, b, c, 2011a, forthcoming). This methodology involves an interactive interview process where the interviewee is not simply a passive informant but also aids in the construction of a value network representation of organizational social interactions. This is the first of several visual representations, others involving storylines, specific depictions of deliverable exchanges, and assets being created and used. Graphviz software also enables the construction of figures to further represent what goes on in the organizations.

Langley (1999) supplies an in-depth review of strategies for theorizing from processed data, advocating that one should not be limited to the use of only one strategy, that "multiple strategies are often advisable" (Langley, 1999) as each have strengths and weaknesses "in terms of their capacity to generate theory that is 


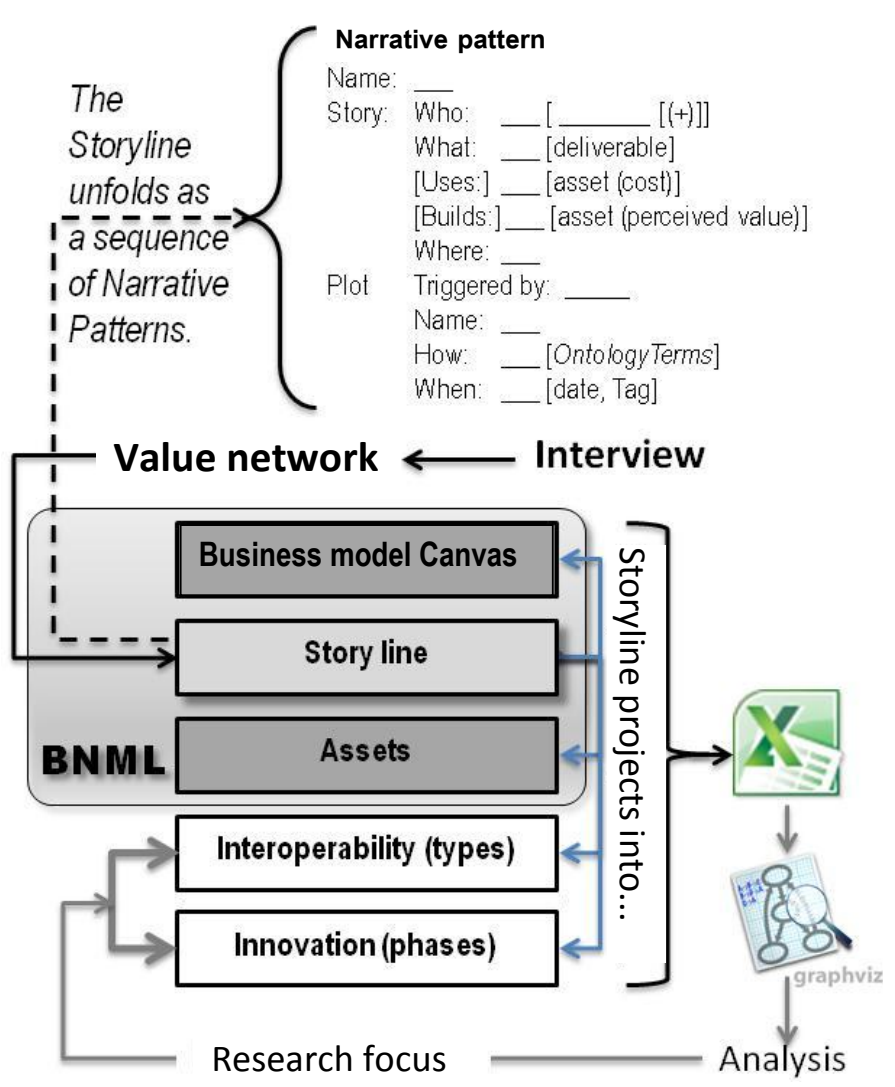

Figure 2. BNML as a pivot between the actual interview and the research analysis.

accurate, parsimonious, general and useful" (Langley, 1999). The concern is with what to do with the data once it has been collected. Langley (1999) provides an approximate ordering of sense making strategies along three dimensions: accuracy, simplicity and generality. The narrative is seen to be the most accurate but least simple and generalizable strategy, the opposite occurring with visual mapping (less accurate but more simple and generalizable), which thus complement each other. We seek a balance between the narrative and visual representations with our BNML (Oliveira and Ferreira, 2010a, b, c, 2011a, forthcoming). We also embed several ontologies (Uschold et al., 1998; Fritscher and Pigneur, 2010; the Unicist ontologies of human learning and innovation, 2012) in our BNML analysis, which thus become a part of it, in order to provide for more standardization across cases. The whole process is illustrated in Figure 2, picturing the BNML as a pivot between the actual interview and the research analysis.

\section{CASE STUDY - IP BRICK}

IP BRICK is a privately-owned software house located in Portugal and founded just over a decade ago. It has fifty full-time employees, twenty-two of whom divided into two research and development (R\&D) departments to produce original innovative products. IP BRICK has annual sales of 4 million Euros (2010), having increased its sales volume by $20 \%$ in relation to 2009 .

Though manufacturing two main product lines for national and international sales and distribution (named herein Product Line 1 which refers to a highly innovative but at the same time low-priced operating system for servers - IPBrick - based on open source software - Linux; and Product Line 2 - referring to other management software for workflow and document management and UCOIP communications - unified communications over IP, a step beyond VOIP - voice over IP - which appeared in the 1990s) the company also commercializes a line of products manufactured by another organization - anti-virus software under the brand name Kaspersky - however in this case in Portugal alone. Sales volume is made up of approximately $50 \%$ of sales of the in-house manufactured products and $50 \%$ of sales of the $3^{\text {rd }}$ party software. IP BRICK has five main functional areas which are: sales, research and development Product Line 1, R\&D Product Line 2, support and implementation, and finance. It is important to note that the average age in the company is low, being 28 years (including the CEO and directors). Employees with no prior working experience are preferred as these individuals tend to not have "bad habits" which might hinder their absorbing IP BRICK's corporate culture (based on knowledge sharing and innovation contributions by all members of the organization). Despite Portugal having gone through a major crisis over the last few years, a fact which has been focused upon by the international media quite consistently, IP BRICK has always returned a profit at year-end and sales have been growing steadily since the year 2000. IP BRICK is considered by competitors in the software industry, and also according to articles in the press, to be highly innovative, despite never having had financial capital injected into the company. The IP BRICK brand is well-known internationally. This is seen to be also due to an annual spending of $15-16 \%$ of sales on R\&D (innovation) activities which contributes to the production of innovative products. Product prices and customer proposals range from 500 to $60.000 €$. Sales margins are lower for the products not manufactured by IP BRICK (10 to $15 \%$ in this case). In sum, IP BRICK's revenue stream comes from software sales, software implementation and support services, and from giving training to partners / software distributors concerning IP BRICK's products.

\section{Data gathering}

Following a kick-off meeting with the $\mathrm{CEO}(\mathrm{PhD})$ and a tour of the IP BRICK facilities, the five functional area directors (each holding a Bachelor degree) were interviewed separately. The interviews were all tape- recorded and had durations of between 60 and $120 \mathrm{~min}$. The researcher followed a script for the interviews and the interview duration also depended upon the issues raised by the interviewee. Interviewees were given the freedom to speak of whatever issues they deemed relevant to the research topic of knowledge creation and innovation. Furthermore, for example, if certain technical aspects of the products manufactured by IP BRICK required further explaining, then the interview would have been prolonged a bit longer. Similarly, if sales and marketing activities required further explanations then this would also have led to more time being spent in the interview. Another aspect which made the interviews rather unique is that the interviewees were asked to help map out the interactions between the internal and external organizational actors of IP BRICK, as concerns their functional department. This involved writing down the names of the actors (roles) on a blank piece of paper and then drawing arrowed lines between these actors, naming the deliverables, both tangible and intangible exchanged between them. Right after the interviews, the researcher would finish this value network mapping (Allee, 2000a, b, 2002, 2008) in his office. After the interviews, some follow-up occurred, namely phone calls to the interviewees and e-mail exchanges to clarify certain interview issues. The result of this data gathering process is shown in Figure 3. This representation is the first step of our BNML - a methodology for performing qualitative research (Alam and 


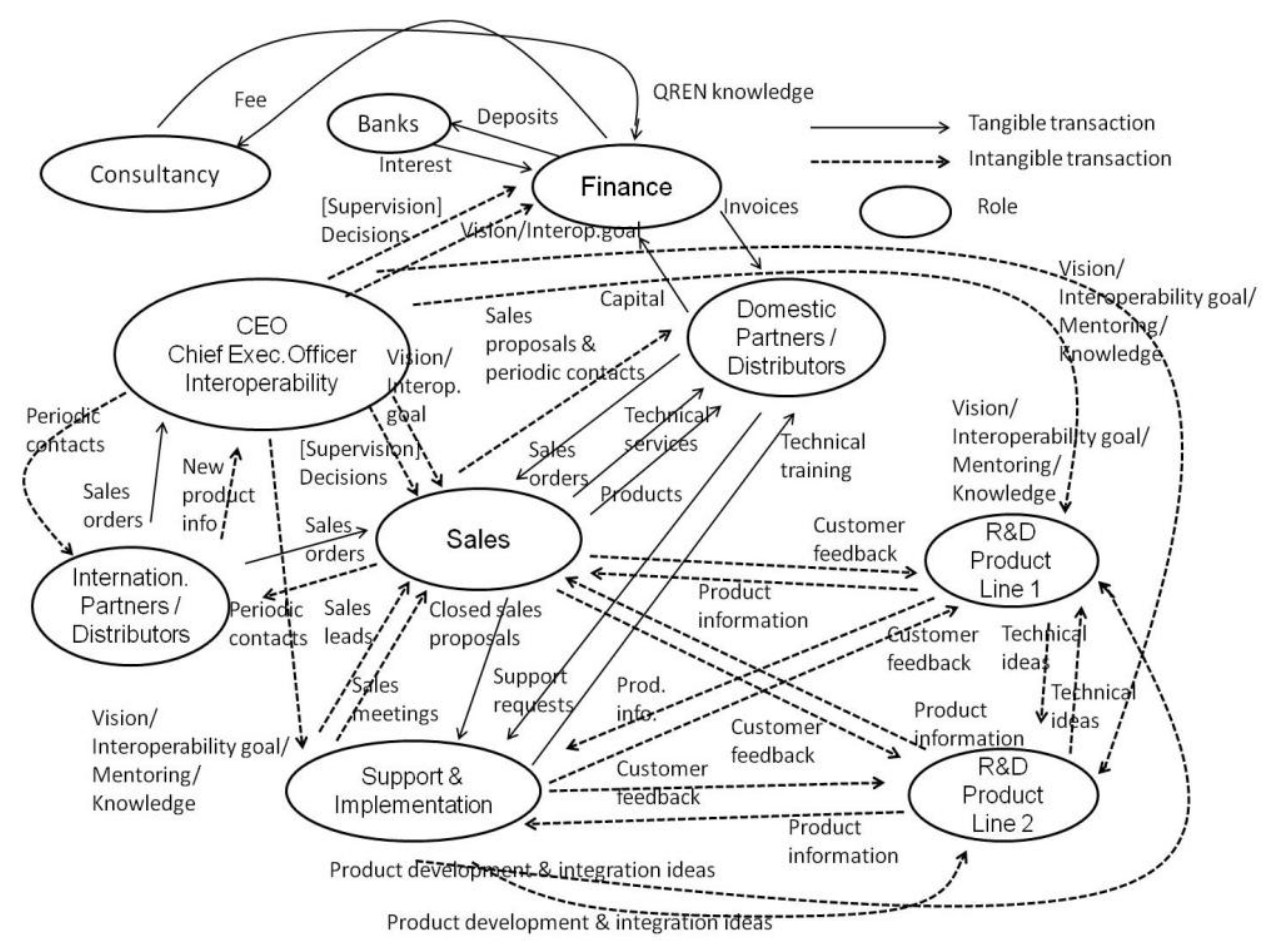

Figure 3. Value network for IP BRICK.

Hoque, 2010).

In Figure 3 , the ovals represent roles or actors in the value network (including the CEO, the five functional departments, as well as other external entities such as international partners / distributors, banks and consultancy firms). The dashed lines show that an intangible deliverable has been exchanged (such as a sales lead or technical ideas) whereas the solid lines show that a tangible deliverable has been exchanged (items such as sales orders, invoices or capital). A balance should exist in the value network between these two types of deliverables, as can be seen in the case of IP BRICK - a reasonable number of each type of deliverable, tangible and intangible, is present in Figure 3 . Note how the CEO has a mentoring relationship with both $R \& D$ departments and with Support and Implementation; on the other hand, the CEO supervises Sales and Finance, with whom closer, more formal relationships thus exist. $R \& D$, seen to be the most important function in the firm by the firm directors, receives important customer feedback from Sales and from Support and Implementation. This feedback (knowledge) will feed the continuous improvement process.

\section{DATA ANALYSIS AND PRESENTATION}

Figure 4 shows our BNML (storyline view), where we can see the different actors (roles) in the value network connected to the creation of an enterprise interoperability capability, an essential aspect contributing to innovation at IP BRICK.

As one can see, not only in Figure 4 but also in Figure 3 , many interactions occur and the CEO, though playing a vital role concerning character development, area control and team development (business patterns evident in Figure 4), IP BRICK's success is due mainly to a concerted group effort. We can also see that interoperability is a goal but also a capability which emerges due to it being company policy (that is required by senior management - the CEO) to share knowledge.

In Figure 4, a series of deliverables are exchanged over time, deliverable exchanges which are carried over directly from Figure 3. Allee's value network thus serves as a basis for this BNML representation, which now has a timeline, an aspect not present in Allee's representations.

The pattern sequence shows a narrative occurring, from character development, communication channels and area control right through to team development. We thus see a story unfolding, IP BRICK's story leading to the creation of value. Uschold et al.'s (1998) ontology adds standardized (and repeatable) detail to the patterns, patterns which are taken from Bjork and Holopainen's (2005) exhaustive listing of patterns, thus saving us the task of coming up with suitable pattern names as they already exist in the literature. This simplifies the qualitative research process. Deliverable exchanges include a vision and decisions passed on to sales:

"The objective of the company is to have a network of partners, a network to distribute our products, not only nationally but internationally also" (Support and implementation director, referring to the decision to develop strong network ties, within as well as across 


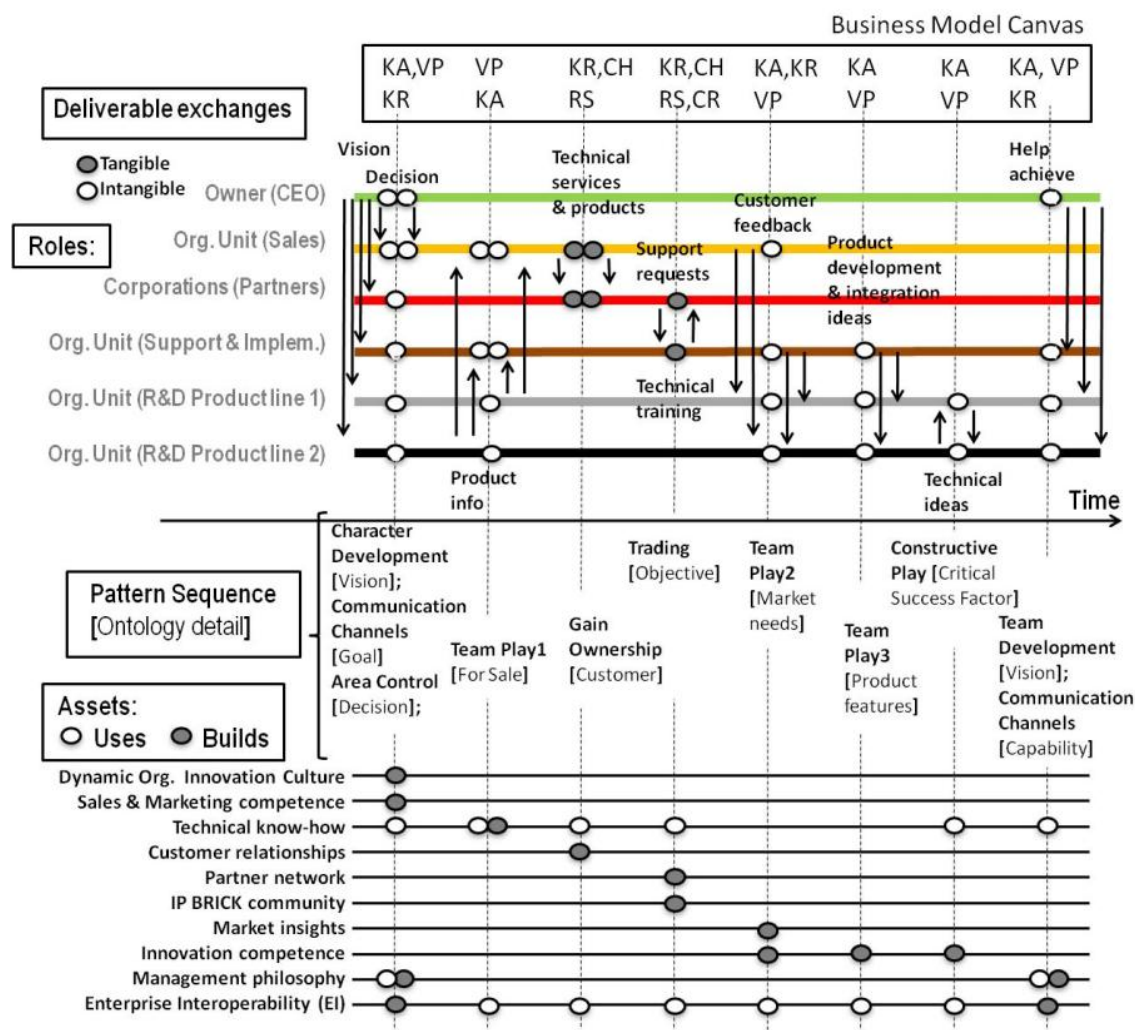

Figure 4. Tangible and intangible deliverable exchanges at IP BRICK along a pattern sequence - building an enterprise interoperability capability at IP BRICK.

borders).

Knowledge sharing occurs easily not only between departments at IP BRICK but also between IP BRICK and its customers. This interoperability capability is a goal set out from the outset by the CEO and has become an integral part of the dynamic organizational innovation culture (the organizational memory).

Product information (deliverable) is also passed on to sales and to support and implementation by the $R \& D$ departments, to prepare them for their contact with clients (partners):

"I would say that the heart of the company is R\&D - the part of the company which involves development and innovation... due to their innovation and to the products which they develop" (again the support and implementation director, referring to how an internal or closed innovation effort drives the company forward, new product information then having to be shared by $R \& D$ especially with those who will come into contact with customers - sales and support and implementation).

In turn, after contact with customers, sales and support and implementation then pass on valuable customer feedback to $R \& D$, feeding the innovation cycle:
"We all together try and achieve sales records... Often we sell without doing hardly anything at all because the product is well-known, because what we do is innovative, because people attribute value to us. We do not sell because there was a salesperson who did everything to close a deal... A lot happens due to the product we have. There are no commissions for salespersons because if I sell the merit of the sale belongs to the salesperson, but also to the person who developed the product because he or she had ideas and developed the product; and the merit is also due to Support and Implementation, who did a good service and implementation job... The merit is everyone's. It is of the whole company acting together... That is why we have a profit-sharing scheme" (Sales Director commenting on the presence of a form of collective mind at IP BRICK, which fuels the exchange and sharing of information and knowledge).

There is a further exchange of product development and integration ideas, as well as of technical ideas, which will lead to new product features and this is part of the patterns team play and constructive play (a critical success factor), patterns which are visible in Figure 4:

"We are all guinea pigs for our own products, which we use internally too" (Finance director referring to how 
internal feedback from using IP BRICK's products is also a source of innovation).

Figure 4 also shows assets used and built along the pattern sequence. The CEO contributes during the patterns character development and area control to the development of a dynamic organizational innovation culture as well as to the development of the essential IP BRICK sales and marketing competence:

"The decision to invest in young people has been an essential aspect of the value-adding activities of the company because these are people who have no old knowledge and who find a company [IP BRICK] for the first time and enjoy being here, they seize the opportunities [given to them]. The younger they are the more I enjoy working with them. They are people who are very available, who enjoy learning, and they don't have any acquired bad habits since they haven't worked for any other companies before. And then they really 'feel' the company, as it was their first opportunity, and they like the products, they like being a part of this... The company is very young, people are really proud of being here and they really want to be here and contribute as much as they can to help the company" (Sales director referring to the dynamic organizational innovation corporate culture at IP BRICK).

Technical know-how (concerning both tangible products and services offered) is used (asset usage is made evident by the white ovals at the bottom of Figure 4) in the whole process of the development of a dynamic organizational innovation culture. Technical know-how is also used during the pattern team play 1 , when knowledge-sharing occurs between R\&D Product Line 1, $R \& D$ Product Line 2 and sales and support and implementation. This normally occurs during face-to-face interactions but there are several software applications which also make this exchange of information possible. Gaining ownership of customers (another pattern) involves using technical know-how and building customer relationships. Actual trading (another pattern) involves using technical know-how (sales competence and product knowledge), to build a partner network and an IP BRICK community. The patterns team development and communication channels end the pattern sequence in Figure 4 and result in the building of a management philosophy, which is the visionary CEO's view for the company's future:

"We have here [at IP BRICK] an innovation culture, for creating new things, we are constantly creating. Our two main products have always to accompany the needs of our partners, of our customers. We have to see what they want. Because they at times say "This is good but it lacks this" and we reply "no problem, we'll develop it." We really have that type of culture, continuous innovation. In our industry it is impossible for our product to stop evolving." (Finance Director).

Finally, the business model Canvas (Fritscher and Pigneur, 2010; Osterwalder and Pigneur, 2010; Oliveira and Ferreira, 2011b) is also evident in Figure 4 - each pattern corresponding to business Canvas building blocks. Note that the value proposition (VP) and the key activities (KA) which it involves are present in most patterns, which is indicative of the company's focus on creating value. A concern is also evident for developing key resources (KR) (such as enterprise interoperability) linked to the value proposition of the company by the CEO. Finally, the distribution channel $(\mathrm{CH})$ is seen to be via sales by the sales department to partners as well as through the provision of other services (such as training) provided to these same partners by support and implementation - and which all generate revenue streams (RS). Trading builds a partner network and an IP BRICK community, based on customer relationships (CR) - which are also part of the business model Canvas.

Table 3 shows other interview evidence leading up to the ten business patterns identified and visible in Figure 4. The business patterns have also been categorized in Table 3 according to the phase to which they correspond in the knowledge management cycle (Jashapara, 2004). Individual as well as organizational learning will occur (especially in social interactions where the CEO is involved), due also to the high levels of motivation in the firm (made evident in the interview interactions - in particular the profit-sharing scheme is an external motivating force "viewed as a means to influence the organizational culture" (Bushardt et al., 2007) - but high levels of internal motivation also exist, the desire to make a difference in an innovation-producing company). Information acquired at university [a somewhat passive process which involved IP BRICK's young graduates normally quite recently, who were "told" (Jashapara, 2004) what is best at university] is transformed at this stage into knowledge applicable in the workplace due to the hands-on approach at IP BRICK (young employees are given considerable responsibility at IP BRICK). Knowledge sharing (for example by the R\&D departments) is part of the dynamic organizational innovation culture (a major asset which is built and is evident in Figure 4); knowledge which will be leveraged (by sales and by support and implementation) to produce revenue streams for IP BRICK. The cycle continues as the $R \& D$ departments evaluate strategic knowledge to ensure a continuous flow of innovative products in demand by the market:

"All of our products evolve like that, always with customers already interested in them. We never do anything very spectacular and which no one will buy. We develop according to what we observe" (sales director commenting on IP BRICK's absorptive capacity) 
Table 3. Other interview evidence leading up to the ten business patterns related to the knowledge management cycle (Jashapara, 2004) at IP BRICK.

\begin{tabular}{|c|c|c|}
\hline Business Pattern & Phase in the knowledge management cycle & Interview evidence \\
\hline $\begin{array}{l}\text { Character } \\
\text { development }\end{array}$ & $\begin{array}{l}\text { Discovering knowledge (involves individual } \\
\text { learning) }\end{array}$ & $\begin{array}{l}\text { "Internationally, despite there being other people involved internally, the main sales } \\
\text { role and sales contacts are performed by our CEO. Our CEO helps sales including } \\
\text { the sales director, giving a push when necessary, especially in bigger deals." } \\
\text { (Finance Director) }\end{array}$ \\
\hline $\begin{array}{l}\text { Communication } \\
\text { channels }\end{array}$ & $\begin{array}{l}\text { Generating knowledge (involves information } \\
\text { distribution and interpretation) }\end{array}$ & $\begin{array}{l}\text { "There are several ways to promote product innovation, including the observations } \\
\text { which reach us from our partners, when they are installing our products; they } \\
\text { mention problems, ask questions which we pass on to R\&D as possible ideas for } \\
\text { programming and to allow for new product functionality" (Support and } \\
\text { Implementation Director) }\end{array}$ \\
\hline Area control & $\begin{array}{l}\text { Generating knowledge (involves organizational } \\
\text { learning) }\end{array}$ & $\begin{array}{l}\text { "Our CEO coordinates everything, having a more direct intervention in sales and } \\
\text { finance. He is the heart of our five departments... In our functional matrix our CEO } \\
\text { replaces the sales director when she isn't in" (Finance Director) }\end{array}$ \\
\hline Team play 1 & $\begin{array}{l}\text { Sharing knowledge (part of the organizational } \\
\text { culture) }\end{array}$ & $\begin{array}{l}\text { "The two main products which we develop involve a lot of information and } \\
\text { functionality which needs to be managed and passed on." (R\&D1 Director) }\end{array}$ \\
\hline Gain ownership & $\begin{array}{l}\text { Leveraging knowledge (which contributes directly } \\
\text { to the revenue stream) }\end{array}$ & $\begin{array}{l}\text { "We often sell without doing almost anything because the product is well-known, } \\
\text { because this is innovative" (Sales Director) }\end{array}$ \\
\hline Trading & $\begin{array}{l}\text { Leveraging knowledge (which contributes directly } \\
\text { to the revenue stream) }\end{array}$ & $\begin{array}{l}\text { "Support and implementation spend a lot of time with our partners. Our products } \\
\text { have lots of different solutions. And there are a lot of services associated to our } \\
\text { products. We need to train our partners so that they can sell technical training to } \\
\text { end customers" (Sales Director) }\end{array}$ \\
\hline Team play2 & $\begin{array}{l}\text { Sharing knowledge (part of the organizational } \\
\text { culture) }\end{array}$ & $\begin{array}{l}\text { "There are various ideas that appear that promote product innovation including } \\
\text { observations that come from our partners during installations. Problems, questions, } \\
\text { difficulties encountered are passed on by support and implementation to R\&D for } \\
\text { programming and to develop new functionality" (Support and Implementation } \\
\text { Director) }\end{array}$ \\
\hline Team play3 & Evaluating knowledge (strategic perspective) & $\begin{array}{l}\text { "Sometimes customers aren't even aware of their needs and IP BRICK anticipates } \\
\text { them." (R\&D2 Director) }\end{array}$ \\
\hline Constructive play & Evaluating knowledge (strategic perspective) & "The two R\&D Directors exchange technical information." (R\&D2 Director) \\
\hline Team development & $\begin{array}{l}\text { Generating knowledge (involves organizational } \\
\text { learning) }\end{array}$ & $\begin{array}{l}\text { "Our CEO is a source of innovation; our products were practically born from his } \\
\text { ideas." (Support and Implementation Director) }\end{array}$ \\
\hline
\end{tabular}

Figure 5 is a diagram (made using Graphviz software) where the plots explain the organizational narrative at IP BRICK. There is a parallel between the plots in Figure 5 and the process view (activities view) of an organization. Figure 5 is a second component of BNML - the plot view - adding to the storyline view in Figure 4. BNML is an integration of the two views. Figure 5 was inspired by Aveiro and Tribolet (2006) - who set out to "propose an ontology for the organizational function concept, anchored on the fundamental concept of activity" (Aveiro and Tribolet, 2006) - activities which aim at accomplishing a specific task "given an initial state... [and] a recognizable end-state" (Aveiro and Tribolet,
2006).

Figure 5 is thus a functional ontology of the creation of an enterprise capability (at IP BRICK). It is the result of previous parameterization in an Excel sheet according to the BNML mapping (Figure 4). Patterns are triggered by actors (CEO, human resources, unit directors, partners, and departments such as sales, R\&D1, R\&D2, support and implementation) represented by the red octagons on the left of Figure 5. Certain inputs (In-Management Philosophy, In-Technical Know How, In-Interoperability Competence) along with the actor interventions feed into the various plots (how and when the Vision, Goal, Vision_and_Communication Capability, Decision, Market 


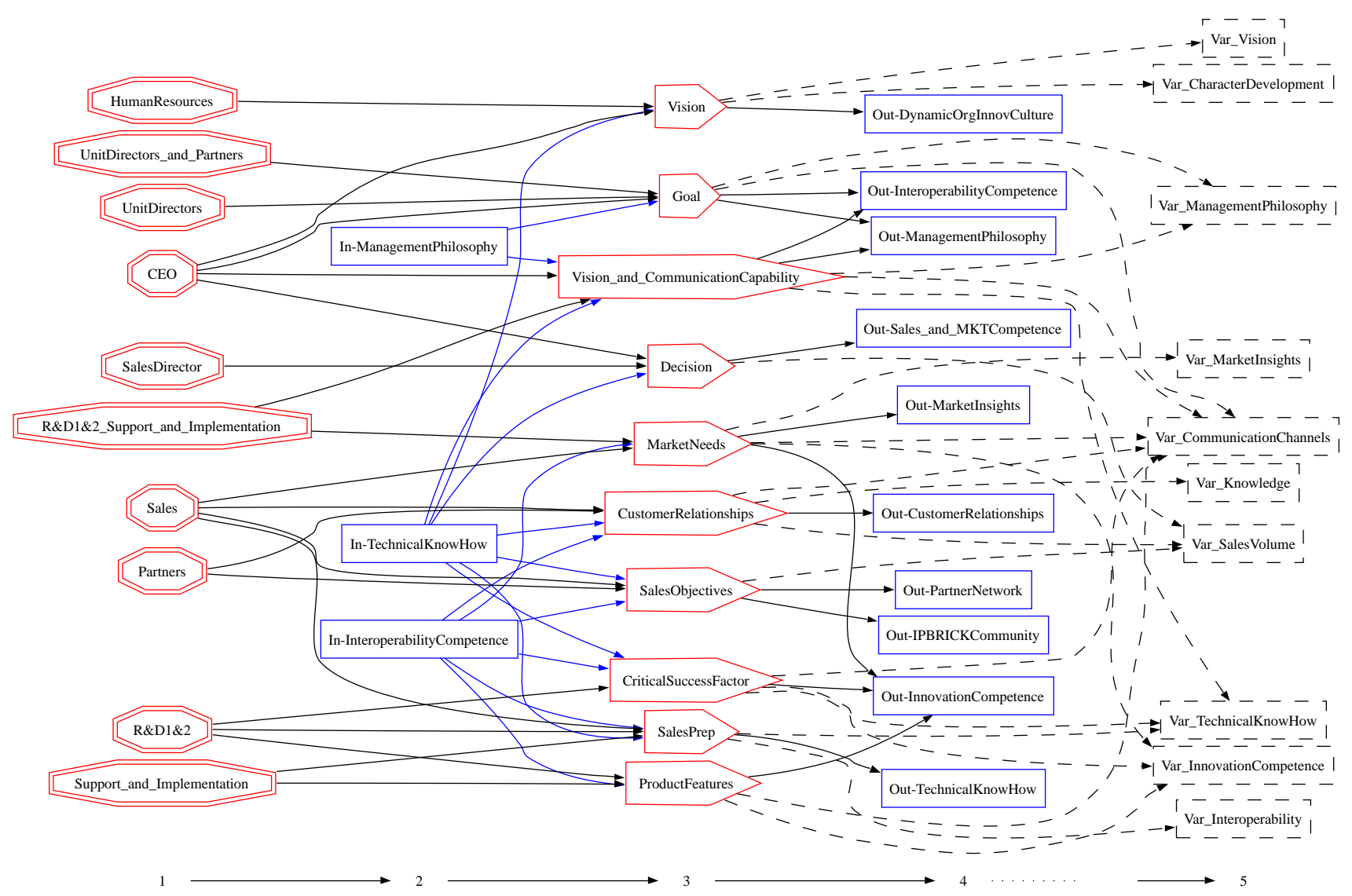

Figure 5. A functional ontology (BNML plot view) of the creation of an enterprise capability at IP BRICK.

Needs, Customer Relationships, Sales Objectives, Critical Success Factor, Sales Prep, and Product Features are achieved) represented by the red arrowed boxes in the center of Figure 5. Plots show how IP BRICK solves the major issues. Issues IP BRICK is confronted with in order to deliver competitive and innovative products and services to market. For this to occur, the plots will have certain outputs (such as a dynamic organizational innovation culture, an interoperability competence, a management philosophy, a sales and marketing competence, market insights, customer relationships, a partner network, an IP BRICK Community, an innovation competence, and technical know-how). The inputs and outputs mentioned above are simply the assets present in Figure 4. The inputs are assets used (represented by the white oval shapes at the bottom of Figure 4), the outputs are the assets built (represented by the grey oval shapes at the bottom of Figure 4). These outputs are in turn controlled by key state variables (Var-Vision, Var-Character Development, Var_ManagementPhilosophy,Var_MarketInsights,Var_Co mmunicationChannels,Var_Knowledge,Var_SalesVolume ,Var_TechnicalKnowHow,Var_InnovationCompetence, Va r_Interoperability) which indicate (to senior management) whether there has been a departure from the norm. If there has been a departure from the norm resilience dynamics (Aveiro and Tribolet, 2006) come into play the organization is self-maintained to survive via (new) microgenesis processes or, in other words, the implementation of micro changes to secure adaptation to the environment (Aveiro and Tribolet, 2006). As an example of a reading of Figure 5, the CEO, unit directors, and partners (actors triggering the event) use the management philosophy (input) to achieve the goal (plot) of having an interoperability competence (output). The goal plot uses the state variables Var_Management Philosophy and Var_Communication Channels to detect departures from the norm. These state variables can be measured using a variety of management tools. Another example of how Figure 5 can be read involves the output dynamic organizational innovation culture. This output is triggered by human resources and the CEO. Technical know-how is used as an input to the vision plot. The state variables Var_Vision and Var_Character Development provide feedback on the evolution of this activity. Finally, we thus have seen how the functional ontology in Figure5 involves five steps - indicated at the bottom of the figure - actors and inputs trigger plots which lead to outputs 


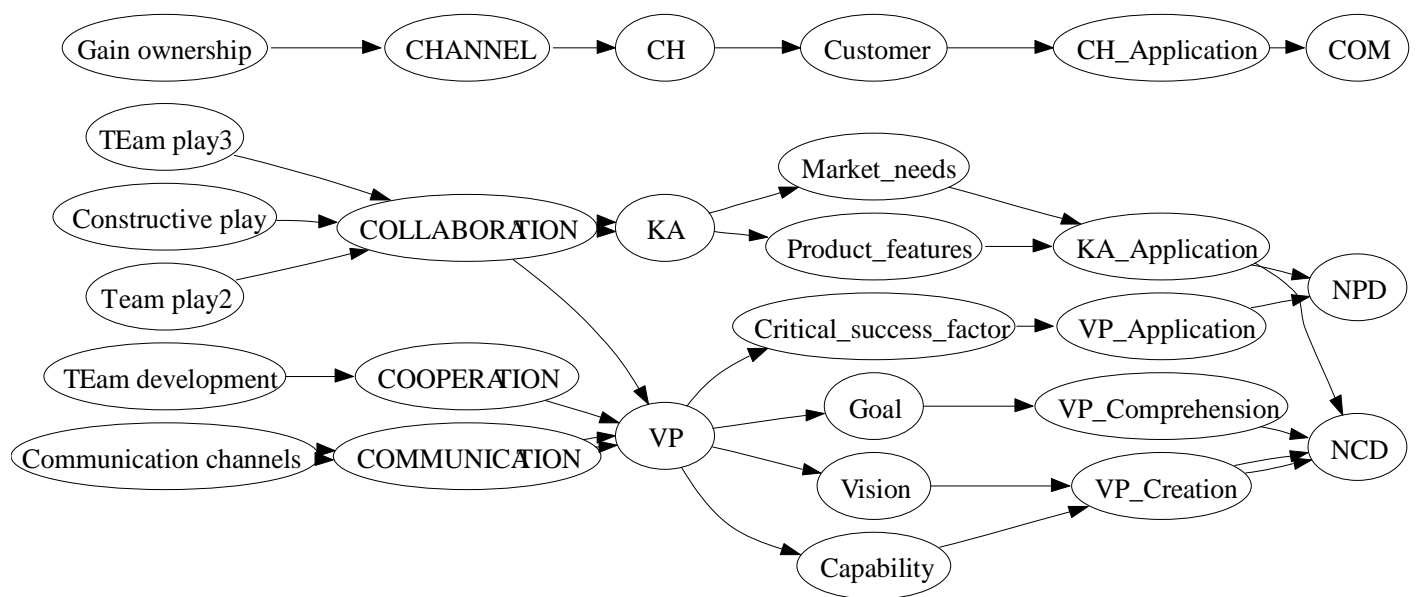

Figure 6. A BNML pattern sequence showing enterprise interoperability types as antecedents of the three innovation phases.

which are in turn monitored by state variables.

Figure 6 is another detailed view of IP BRICK provided by Graphviz software and derived from an Excel IP BRICK parameterization sheet - a parameterization involving business patterns (Bjork and Holopainen, 2005), El types ( $\mathrm{Li}$ et al., 2008), the business model Canvas (Fritscher and Pigneur, 2010; Osterwalder and Pigneur, 2010; Oliveira and Ferreira, 2011b), Uschold et al.'s (1998) enterprise ontology, Unicist ontologies and the phases of innovation, all woven together in the BNML representation. Figure 6 is, in effect, a collection of key terms or strings which explain how innovation occurs at IP BRICK.

Uschold et al.'s (1998) enterprise ontology appears with terms such as customer, market needs, product features, critical success factor, goal, vision and capability (Figure 6). We also use Unicist ontologies and the Unicist ontology of human learning (with terms such as knowledge, to act, application and analytical stage) is seen to be appropriate given that, at IP BRICK:

"Training and development while on the job is continuous, for example for trainees who really learn while they are here... about our products, about our development support tools which they will need to use, about how to improve their computer programming... and we also have other official training sessions for groups of employees, here at IP BRICK - training in languages, leadership, [organizational] behavior, sales... The CEO establishes the rules which we need to follow and in terms of leadership we also see how our CEO acts and try to act in the same way with our teams, we all learn a lot from him... Another example of our development is how Sun Tzu's book The Art of War was given to all of the directors by the CEO. The book has many interesting ideas and topics which we can apply here in our day-to-day functioning" (R\&D1 Director)

On the left hand side of Figure 6, the six patterns gain ownership, team play 3 , constructive play, team play 2 , team development and communication channels feed into four enterprise interoperability types - channel, collaboration, cooperation and communication. Thus we can see that interoperability is an antecedent leading to the three phases of innovation COM (innovation commercialization), new product development (NPD), and new concept development (NCD) present on the right side of Figure 6 - thus, answering our research question. So, for example, COM (innovation commercialization phase) is fed by the gain ownership pattern which involves CHANNEL interoperability information-and-communication-technology-enabled, or ICT-enabled:

"Our key activities are extremely influenced by ICT which we not only sell but also use to manage knowledge internally... Even our quality management system, which is normally associated at other companies to a lot of paper, a lot of files, here we don't have any paper at all. All of our processes are implemented in our software applications. More than $95 \%$ of the time we are able to do without paper" (R\&D2 Director)

The customer is a key word here [(Uschold et al., 1998), ontology term] for whom the communication channels developed are applied ( $\mathrm{CH} \_$Application). Another view of Figure 6 involves team development, which in turn involves COOPERATION (interoperability) linked to the value proposition (VP) and leading ultimately to NCD.

The reality in Figure 6 is a direct result of the IP BRICK interviews / case study. In sum, El involves interactions 


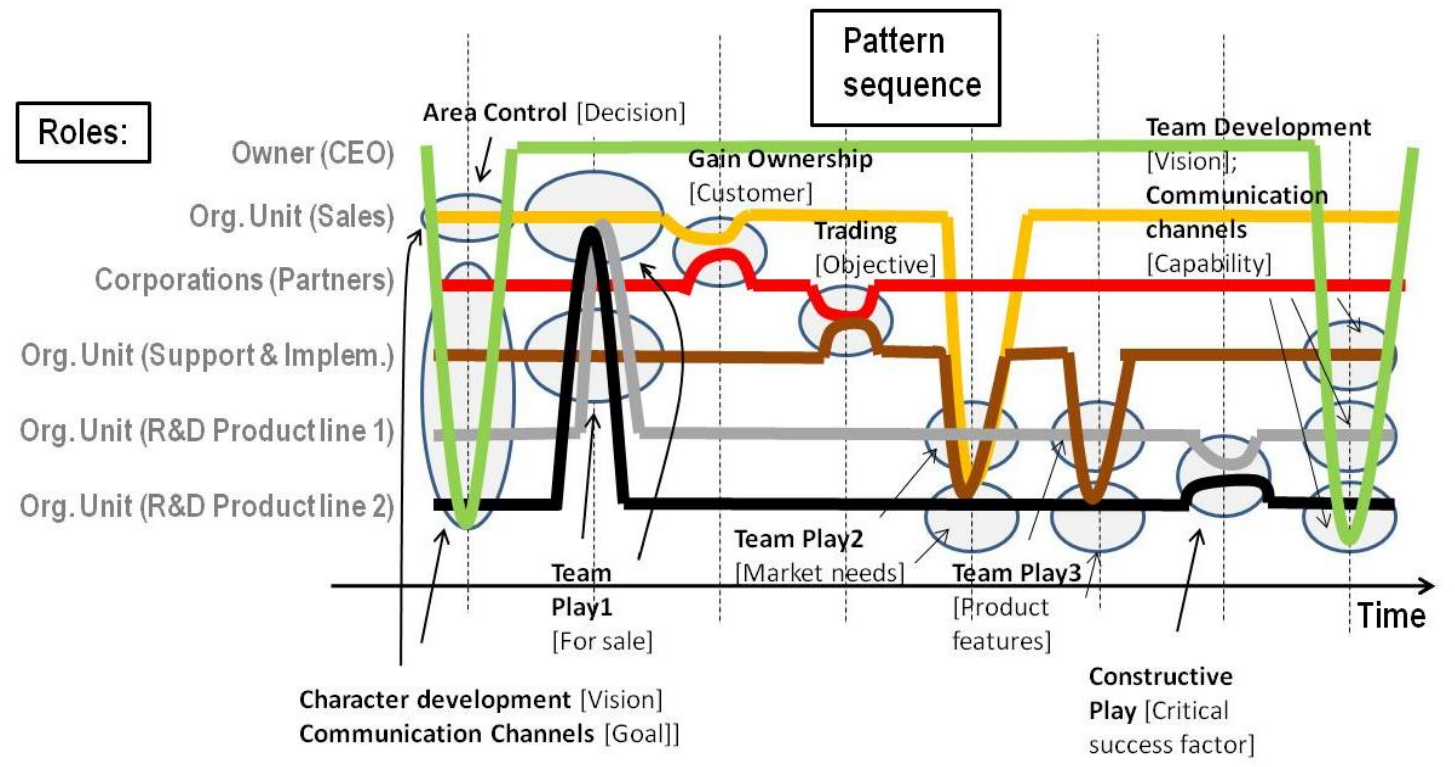

Figure 7. BNML representation showing social interaction between roles along a pattern sequence.

including communication, channel, cooperation and collaboration within, as well as between, firms operating in the marketplace (Li et al., 2008). Figure 6 unveils how this interoperability competence leads to innovation. Miller (2000) stated that "To be interoperable, one should actively be engaged in the ongoing process of ensuring that the systems, procedures and culture of an organization are managed in such a way so as to maximize opportunities for exchange and re-use of information, whether internally or externally." This aspect in particular - interoperability - is very visible at IP BRICK and was mentioned often during the interviews of the company directors, for example by the finance director as follows:

"We are working, including the CEO, to make all of the departments interact, to make them work in synchrony. We aim for this coordination because the customers are the same for all of us and we need them to be satisfied at all levels."

Figure 7 represents, indeed emphasizes, how the actors' storylines interact along the business narrative, giving life to a pattern sequence, this being another visual BNML representation. The grey clouds represent times when the actors (roles) come together, socializing for value creation purposes. Despite the fact that Figures 4 through 7 represent the same narrative, the latter is very useful for the visualization of what actually happens as it puts in evidence the actual interactions. Thus, the CEO (green line) interacts with all of the other actors present in Figure 7. The pattern team play 1 , for example, involves interactions at two moments, between the $R \& D$ departments and support and implementation and between the R\&D departments and sales. Then ownership is gained of customers (partners) by Sales, as a result of the preceding team play during which knowledge sharing occurred. Trading (an objective) then follows, another social interaction between partners and support and implementation. Team play 2 and team play 3 , as well as constructive play, are part of a pattern sequence that builds an innovation competence at IP BRICK (an asset visible in Figure 4) as follows:

"My work involves innovation management, an orientation, a definition of the product development paths to follow given to the R\&D2 team, made up by seven people. I will also interact with all of the departments in the company, implementing specific developments or alterations which my colleagues ask for (for example, the support and implementation director, who comes into contact with the customer, implementing our products there and bringing back important information and suggestions which enable us to do our development work properly, here in R\&D). I also might need to intervene in the management of a number of ongoing projects we have... Our goal is to satisfy real customer needs, entirely new and unpredictable situations which appear and are brought to us by sales, for example, which have that routine of coming by R\&D. In view of information presented to us and taking into account what we already have or might come to develop for that situation, we make specific development proposals..." (R\&D2 Director)

The three business patterns - team play 2, team play 3 and constructive play - were described as follows: 
"Being in charge of R\&D involves interacting with all of the departments... salespersons contribute with incremental innovation ideas... R\&D1 director and R\&D2 director communicate constantly - we are always exchanging ideas as our management software product lines, which I am in charge of, are completely based and have their roots in our main product line (operating system). There is a constant need to talk and discuss and exchange ideas so as to correctly orient development, so that both product lines function correctly... We even also speak constantly to the financial department as they are our [internal] customer, we have specific financial area products for the automation of administrative processes as well as customer information management products, which they use and test for us... So we have an ongoing dialogue with the financial director too, to satisfy her needs, to optimize products and functionality she requires, to share project completion dates... And of course we also speak to the CEO" (R\&D2 Director)

The final patterns (team development and communication channels) show, again, how the CEO develops the team further, helping them achieve their goals in a mentoring relationship and promoting communication channels:

"Support and implementation might contact us directly if they are having a lot of problems with something in particular... a configuration at a customer, for example... They will register the problem on TRAC but there is nothing like personal contact, informing and exerting more pressure on our department personally if urgent changes like a program update are seen to be needed. Information technologies, ICT, are useful tools, but there is nothing like a personal approach to issues; we have a lot of things which are registered but the importance of an item might not be evident; if we don't give a quick response to an issue of support and implementation they might then contact us to see how things are evolving: "Are we going to have a quick update or not?" There is that need and sometimes that happens."

\section{The R\&D1 Director stated further that:}

"Our CEO contributes a lot with innovative ideas... A lot of our innovation also comes from feedback from customers/partners/distributors. Interactions especially with the international market are very good for idea generation. Not that we are behind here [in Portugal]... but the dialogue with customers/partners/distributors about our products is very important, it reveals needs which arise, gaps in our products, automation suggestions (for example, only two clicks to fully configure a product)... We also brainstorm and have weekly meetings internally... IPBrick [product line 1 operating system] doesn't stop, it has never stagnated, every day it has new functionality. Problems are solved; something is always being done - always every day." (R\&D1 Director)

\section{Reviewing the methodology applied on IP BRICK: The emergence of an interoperability capability using BNML}

In sum, after the field work and with the material still fresh in their minds the research team created the BNML representations of the data, as mentioned above. The recorded interviews were listened to and the relevant material transcribed to support the patterns identified (in sequence). An Excel table was built and filled with our BNML data for parameterization purposes (the parameterization process - Excel sheet detailing - was repeated until a satisfactory, in-depth level of detail was reached which permitted us to formulate conclusions to our research effort) and from there graphs were developed with Graphviz - graph visualization software (found at http://www.graphviz.org/). We are satisfied that the Figures 4 through 7 and the relevant adjoining narratives provide a means to communicate how interoperability, enabled by ICT, leads to innovation at IP BRICK. Gasser and Palfrey (2007) did state that "one of the reasons why we tend to like interoperability is that we believe it leads to innovation". Though "the relationship between interoperability and innovation, while it likely exists in most cases, is extremely hard to prove" (Gasser and Palfrey, 2007) we believe that with our research we have laid down the foundation for this relationship to be further demonstrated with more in-depth case studies.

The end results of our study were presented first to the CEO and then to the rest of the IP BRICK team. This allowed a validation of our results but also made possible a further in-depth discussion of our findings.

\section{DISCUSSION OF THE CASE IN VIEW OF THE LITERATURE}

Alam (2011) suggests that the discussion of research findings should take into account earlier research, on the one hand, for validation purposes, on the other hand "to provide a standpoint for the current research". We seek to achieve the above in this section.

ICT play a big part in IP BRICK's day-to-day activities, for example for internal process management and for sales purposes, and are in effect a significant part of the organizational culture. In particular, Internet-based tools are a source of business value at IP BRICK, confirming research by Soto-Acosta et al. (2010). The computer systems industry "embraces innovation at a breath-taking rate" (Patterson and Hennessy, 1994) and IP BRICK is no exception. In view of competing products sales is a major challenge (Miettinen et al., 2010) and customer 
collaboration and co-creation (Bhalla, 2011) is essential to innovation output at IP BRICK - Web 2.0 technologies helping to connect and to ensure real-time communication and contributions; countering a tendency within SMEs to have "limited technology systems to store knowledge and information in a useful way" (du Plessis, 2008). Information technology is far from being a centralized function at IP BRICK, decentralized operations occurring in particular due to the leveraging of the Internet - connectivity between users and integration is a major concern (Laurindo, 2002). Indeed, interoperability is defined above as "the ability of a system or an organization to work seamless[ly] with other systems or organization[s] without any special effort" (Mertins et al., 2008), and this is also very evident in our case study findings. We thus see interoperability as being central to future discussions on knowledge management and, in particular, its presence as an antecedent of innovation will also be very important.

IP BRICK's products developed in-house are used by IP BRICK, on the one hand for testing purposes (much as in a laboratory environment) on the other because they permit saving the hiring of further human resources, thus keeping costs down. For example:

1. Pricing information, receipts, invoices, credit notes, are all accessible to customers online every day without further human intervention being necessary (via iPortalDoc Light - an online application which has free-ofcharge access for customers); and products can be purchased online too. This reveals great ease of communication and an interoperability capability.

2. IPTicket is for registering customer service hours (to be used by the finance department), but also for reporting software problems, queries and suggestions directly to IP BRICK's appropriate division (for example, Help-desk or Support and Implementation). Customers as well as employees can access this application which serves as a continuous innovation platform with valuable feedback and insights. Interoperability is also revealed through the use of this application.

From a business standpoint, standalone software product sales have also given way to the "provision of various types of services" (Valtakoski and Ronkko, 2010) and IP BRICK does make product training one of its major goals and sources of revenue streams.

IP BRICK is very forward-looking and paper is kept to a minimum - for every fifty or so documents in a physical paper format (including mainly items received in the post), there will be well over a thousand digital documents exchanged within the company (including email exchanges). Younger employees adhere faster to the "no-paper, all-digital" policy which IP BRICK's organizational culture also seeks to promote in its customers. IP BRICK practices and equally importantly sells what it "preaches". Thus, IP BRICK's organizational culture is instrumental to its survival and growth (Pecujlija et al., 2010), and is a source of competitive advantage not easily imitable by competitors.

What is evident at IP BRICK is a concerted effort to share information and knowledge - revealing, once again, an interoperability capability, between its various departments - in a very positive way, as Lee (2010) stated is so important. In order to create innovative products which the market wants to acquire, consequently creating competitive advantage, knowledge must be managed well (Chen and Chen, 2010). Everyone benefits from this collaboration as IP BRICK has a profitsharing scheme - up to $25 \%$ of the annual profit is distributed amongst employees. The profit-sharing scheme is based on seniority but it is also based on a voting system - employees vote at year-end to determine who has contributed most to the company during the past year and financial compensation will be attributed accordingly. This is not normal (that is, not a regular practice in most companies) especially in Portugal and during a period of crisis. The Co-recipient of the Nobel Prize for Economics in 1993 - Douglass C. North stated that a problem with Portuguese management is that it is authoritarian and does not promote selfgovernment or competition, or the development of human resources (North, 2005), very different to what we see as occurring at IP BRICK. Organizations irrespective of geographical location and culture, would benefit from implementing such a system as we see at IP BRICK, as a performance orientation is also creative and "helps economic accomplishments" (Triandis, 2004).

Organizational learning is closely linked to performance at IP BRICK, confirming research by Bustinza et al. (2010), and is a fundamental contributor to "the ability to innovate [which] has always been an important contributor to organizational success" (Fichman, 2001). Learning is seen to occur faster, especially as concerns the assimilation of the corporate culture, when the human resources are younger and free of "bad habits" (Usunier and Lee, 2005) and this is the case also with IP BRICK. For example, the sales director is 26 years old, has been with the company for four years, and is the eldest in her department. Of particular interest is being able to develop "motivation, concept learning and the development of skills and appropriate scientific attitudes" (Alam et al., 2010). Having said that, the cost of training individuals to become highly skilled and able to consistently contribute to IP BRICK's dynamic organizational innovation culture (a major asset which concerns senior management at IP BRICK and visible in Figure 4) is quite high and so effort must be expended to avoid a "brain and body drain" (Alam and Hoque, 2010) from the firm. A Christmas party where presents are distributed, corporate team-building weekends, an annual award-giving ceremony for IP BRICK's employees, an annual IP BRICK anniversary 
party, having a team of employees enter sports events (such as long distance running) representing the company, promoting social events at the company such as encouraging employees to bring a birthday cake and drinks when it is their birthday, for all to participate in the birthday celebration, and having a TV onsite and ordering in pizza for everyone when Portugal is playing in an important international event such as the World Soccer Cup, are some examples of how IP BRICK achieves this. "The higher the socialization of a member in an organization is, the higher his/her job satisfaction is" (Lee and Yu, 2010; Oliveira and Ferreira, 2011c) and employee retention should follow.

Having a highly qualified CEO, who has acute social and leadership skills, in order to develop the intimacy necessary among employees which will positively impact on innovation performance, is essential (Lee and Yu, 2010). Such a CEO is a source for developing human resources, for developing trusting relationships, and for passing on and creating an all-important vision, management philosophy and corporate culture. UpperEchelon Theory states that there will be a flow of values and beliefs from the leader to the organizational culture (Winston, 2010) and we believe that this is a sustaining element at IP BRICK to counteract Portugal's absence of religious diversity, a characteristic of a dogmatic culture where a low creative orientation and an absence of a performance orientation will tend to be found (Triandis, 2004).

A CEO who also travels extensively abroad to make contact with the main, as well as new, international customer base, but who readily delegates responsibility including for international sales contacts to his sales department, is similarly very important. The CEO that is very aware of advanced customer needs and of what is already available in the software market is thus also a source of product and process innovation, oftentimes even radical innovation, especially, as we mentioned above, due to spending time with people who "have never shared the same ship, but also have never shared the same ocean" (Malhotra et al., 2001). IP BRICK's success is also due to having the courage to internationalize. The main effort involving the search for new business, internationally, is assigned to the CEO, who then passes on sales contacts to his sales team; despite many [software] firms choosing to "internationalize only a little and gradually" (Ronkko and Peltonen, 2010). Currently, at IP BRICK, international business accounts for more than half of annual sales (Pereira, 2011).

\section{CONCLUDING REMARKS ABOUT BNML: INTEROPERABILITY AS AN ANTECEDENT TO INNOVATION}

BNML was a very important research tool used in our research. It has two views both evident in Figure 4 (storyline view) and Figure 5 (plot view). By systematically making evident who the organizational actors are, who they interact with, what deliverables they exchange in the process, the assets built and used over a pattern sequence, and along the business model Canvas building blocks (Figure 4), we address a number of issues which normally occupy a much more significant amount of time in qualitative research efforts. Furthermore, the plot view [inspired in Aveiro and Tribolet's (2006) functional ontology - Figure 5] can lead to the analysis (using Graphviz software) in Figure 8 where we can see that the interoperability competence (input) leads to (is an antecedent of) the building of an innovation competence. In effect, in Figure 8, we have a BNML representation where we can see actors (for example, Sales), inputs (for example, interoperability competence), outputs (for example, innovation competence), plots (for example, sales objectives), patterns (for example, trading), state variables (for example, Var_SalesVolume) and assets (for example, interoperability competence) all in the same representation - here, in sum, we showed how the asset interoperability competence is used to build an asset entitled innovation competence. It is important to note how the key state variables (such as Var_Innovation Competence and Var_Interoperability) indicate to the CEO whether micro changes (mocrogenesis processes) need to be implemented to secure the organizationenvironment fit (Aveiro and Tribolet, 2006).

Furthermore, in Figure 8 the patterns trading, gain ownership, team play 1 , team play 2 , and team play 3 are each dependent on technology, using the interoperability competence which then leads to innovation.

Figure 9 shows the integration of the plot view and the storyline view. Both views are needed for organizational coherence and both comprise our BNML. For example, in Figure 9, we can see how the CEO is concerned with the character development of his staff via a microgenesis process.

\section{SUGGESTIONS FOR FUTURE RESEARCH}

We have, thus, continued research focusing on small software firms as addressed by Miettinen et al. (2010) small firms which face particular growth challenges. According to Miettinen et al. (2010) human resource management (HRM) is the greatest challenge for these small firms acting in the software services industry and this is a major concern of IP BRICK's CEO and directors, as we have seen above; in the hiring process, in the development and retention mechanisms of the best employees, as well as concerning the indoctrination of new organizational members into the organizational culture - where interoperability plays a major role. Other in-depth analyses of such HR processes are seen to be 


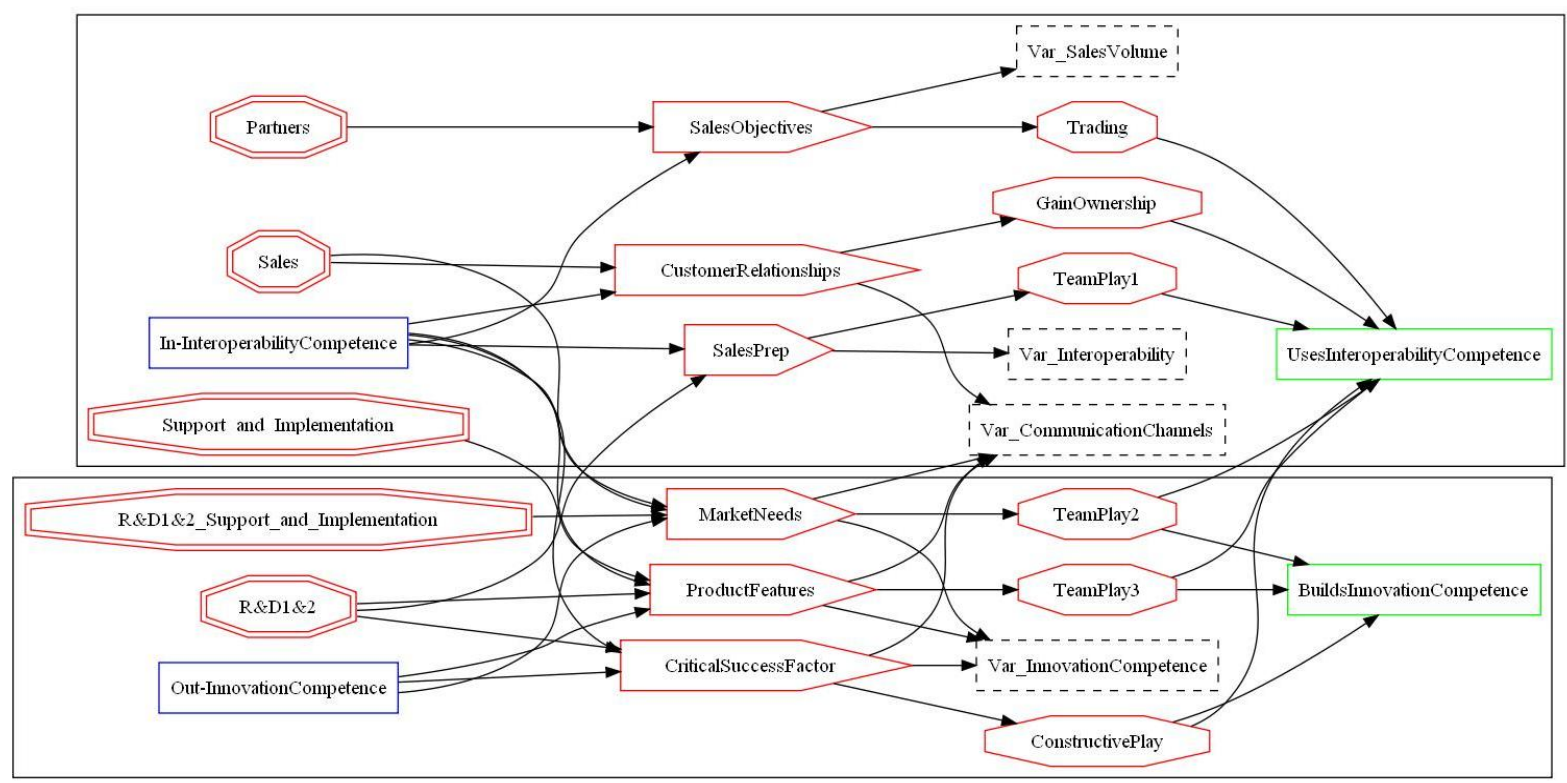

Figure 8. BNML - Plot view of how interoperability leads to innovation.

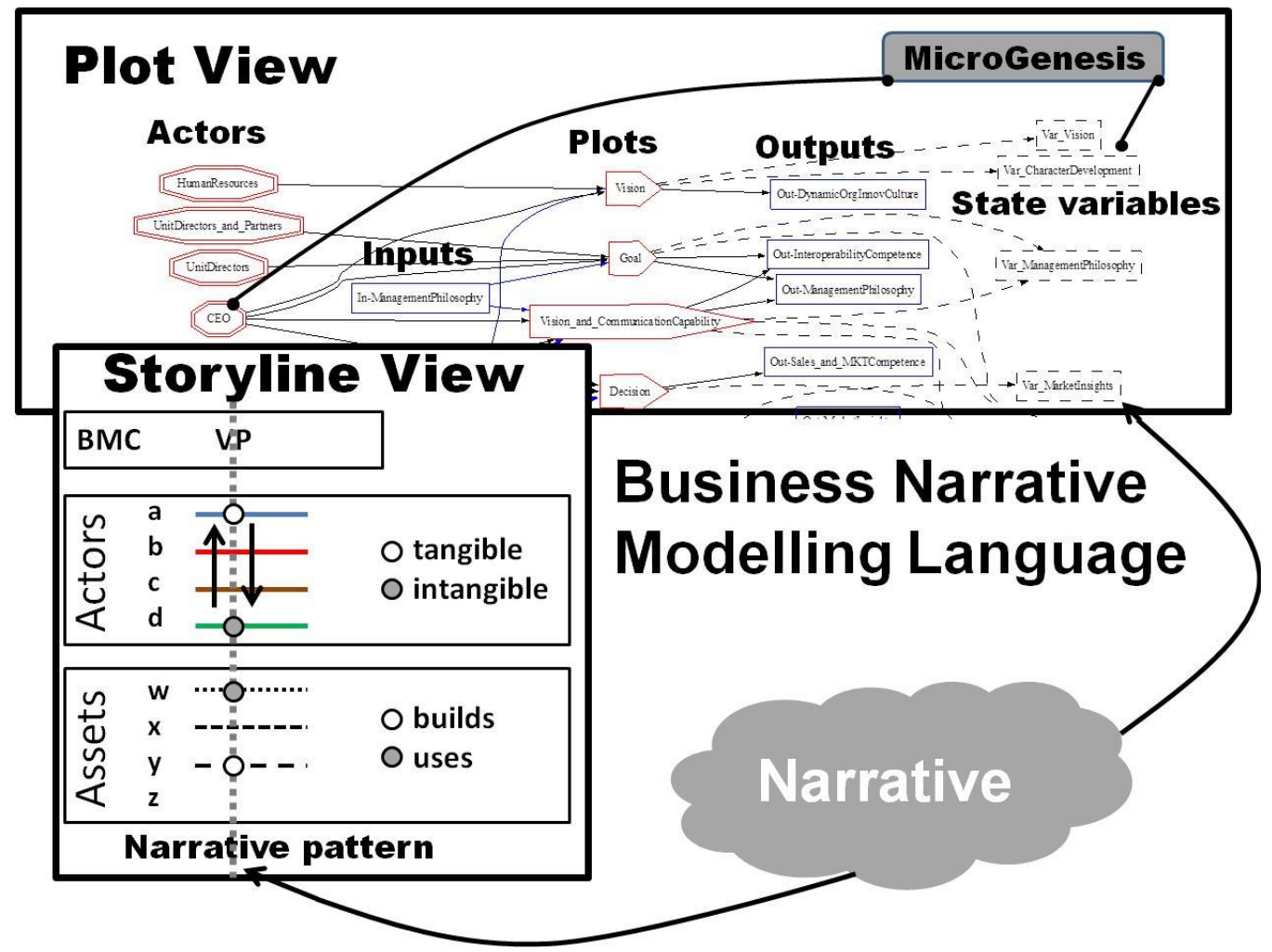

Figure 9. Integrating storyline and plot BNML views.

necessary. Furthermore, we used the BNML and in so doing significantly decreased the time and effort necessary to make sense of the qualitative data gathered. We thus suggest that other authors use BNML 
in their research efforts.

\section{ACKNOWLEDGEMENTS}

The research team would like to thank the interviewees at IP BRICK who spoke so openly to us: Susana Pinheiro (Sales Director), Anabela Santos (Finance Director), Hélder Rocha (Support and Implementation Director), Miguel Ramalhão (R\&D1 Director) and Telma Salgueiro (R\&D2 Director). Finally, we would also like to thank Professor Raúl Oliveira (CEO of IP BRICK) for having opened the doors of his company to us and for having participated in the various research-related meetings and subsequent validation process. We are eternally indebted to you all. Finally, our thanks go to the anonymous reviewers and to the Editor of the African Journal of Business Management whose help enabled us to greatly improve on the quality of our manuscript.

\section{REFERENCES}

Alam GM (2011). A further editorial guideline for writing manuscript in the field of social science: A special perspective for African Journal of Business Management (AJBM). Afr. J. Bus. Manage., 5(1): 4.

Alam GM, Hoque KE (2010). Who gains from "brain and body drain" business - Developing/developed world or individuals: A comparative study between skilled and semi/unskilled emigrants. Afr. J. Bus. Manage., 4(4): 534-548.

Alam GM, Oke OK, Orimogunje T (2010). Volumetric analysis and chemistry students performance: Combined influence of study habit, physiological and psychological factors. Sci. Res. Essays, 5(11): 1325-1332.

Allee V (2000a). Reconfiguring the value network. [online version available at http://www.vernaallee.com/VA/Library.htm on 16-062010]. J. Bus. Strat., 21(4): 1-6

Allee V (2000b). The value evolution - Addressing larger implications of an intellectual capital and intangibles perspective. J. Intel. Capital, $1(1): 17-32$

Allee $\mathrm{V}$ (2002). A value network approach for modelling and measuring intangibles. Paper presented at Transparent Enterprise, Madrid, November.

Allee V (2008). Value network analysis and value conversion of tangible and intangible assets. [online version available at http://vernaallee.com/VA/Library.htm on 16 June 2010 on 16-062010]. J. Intel. Capital, 9(1): 5-24

Almeida IIS (2010). A utilização de uma linguagem de modelação de narrativa de negócio no processo de consultoria estratégica (caso de estudo na Diafresh). Master's dissertation successfully submitted to FEUP - Faculdade de Engenharia da Universidade do Porto, September.

Amabile TM (1997). Motivating creativity in organizations: on doing what you love and loving what you do. Calif. Manage. Rev., 40(1): 39-58.

Aveiro D, Tribolet $J$ (2006). An ontology for organizational functions: The recursive self-maintenance mechanism of the enterprise. $10^{\text {th }}$ IEEE International Enterprise Distributed Object Computing Conference Workshops (EDOCW'06).

Baptista R, Escária V, Madruga P (2008). Entrepreneurship, regional development and job creation: The case of Portugal. Small Bus. Econ., 30: 49-58.

Bhalla G (2011). Collaboration and Co-creation - New platforms for marketing and innovation. Springer, New York, NY, USA.

Bjork S, Holopainen J (2005). Patterns in game design. Charles River Media, Hingham, MA, USA.

Bonabeau E (2009). Decisions 2.0: The power of collective intelligence.
MIT Sloan Manage. Rev., 50(2): 45-52.

Brown AD (2006). A narrative approach to collective identities. J. Manage. Stud., 43(4): 731-753.

Brown AD, Currie $G$ (2003). A narratological approach to understanding processes of organizing in a UK hospital. Hum. Relat., 56(5): 563586

Bryman A (1989). Research methods and organization studies. Routledge, New York, USA.

Bushardt SC, Lambert J, Duhon DL (2007). Selecting a better carrot: Organizational learning, formal rewards and culture - A behavioral perspective. J. Organ. Cult, Commun. Confl., 11(2): 67-79.

Bustinza OF, Molina LM, Arias-Aranda D (2010). Organizational learning and performance: Relationship between the dynamic and the operational capabilities of the firm. Afr. J. Bus. Manage., 4(18): 18: 4067-4078.

Camarinha-Matos LM (2008a). Advances in collaborative networked organizations. In: Azevedo A (Ed.), Innovation in manufacturing networks. BASYS 08 Conference Proceedings. 8th IFIP International Conference on Information Technology for Balanced Automation Systems. June 23-25, Porto, Portugal, pp. 3-16.

Camarinha-Matos LM (2008b). Emerging collaboration forms and further research needs. In: Camarinha-Matos LM, Afsarmanesh $\mathrm{H}$, Ollus $M$ (Eds.), Methods and tools for collaborative networked organizations. Springer, New York, NY, USA, pp. 513-528.

Camarinha-Matos LM, Afsarmanesh $\mathrm{H}$ (2005a). Brief Historical Perspective for Virtual Orgnanisations. In: Camarinha-Matos L, Afsarmanesh H, Ollus M (Eds.), Virtual Organisations: Systems and Practices. Springer, New York, NY, USA.

Camarinha-Matos LM, Afsarmanesh H (2005b). Collaborative networks: A new scientific discipline. J. Intel. Manuf., 16: 439-452.

Camarinha-Matos LM, Afsarmanesh H (2007). A comprehensive modeling framework for collaborative networked organizations. J. Intel. Manuf., 18: 529-542.

Camarinha-Matos LM, Afsarmanesh H (2008). Collaborative networks: Reference modeling. Springer, New York, NY, USA.

Cash Jr J, Earl M, Morison R (2008). Teaming up to crack innovation and enterprise integration. Harv. Bus. Rev., pp. 90-100. November.

Chen I-S, Chen J-K (2010). How to manage knowledge well? Evidence from the life insurance industry, Afr. J. Bus. Manage., 4(17): 4: 36053617.

Chesbrough H (2007). Open Business Models: How to Thrive in the New Innovation Landscape. Harvard Business School Press, USA.

Christensen CM, Raynor M (2003). The innovator's solution - Creating and sustaining successful growth. Harvard Business School Press, Boston, MA, USA.

Chu H-C, Chen M-Y, Chen Y-M (2009). A semantic-based approach to content abstraction and annotation for content management. Expert Syst. Appl., 36(2): 2360-2376.

Corbin J, Strauss A (2008). Basics of qualitative research - Techniques and procedures for developing grounded theory. $3^{\text {rd }}$ ed. SAGE Publications, Inc, California, USA.

Dini P, Lombardo G, Mansell R, Razavi AR, Moschoyiannis S, Krause P, Nicolai A, León LR (2008). Beyond interoperability to digital ecosystems: regional innovation and socio-economic development led by SMEs. Int. J. Technol. Learn. Innov. Dev., 1(3): 410-426.

Doumeingts G, Chen D (2003). Interoperability development for enterprise applications and software, in building the knowledge economy, Part 1, Cunningham et al. (Eds.), IOS Press, Amsterdam.

Dubé L, Paré G (2003). Rigor in information systems positivist case research: Current practices, trends, and recommendations. MIS Q., 27(4): 597-635.

du Plessis $M$ (2008). What bars organisations from managing knowledge successfully? Int. J. Inform. Manage., 28(4): 285-292.

Dyer J, Nobeoka K (2000). Creating and managing a high-performance knowledge-sharing network: The Toyota case. Strat. Manage. J., 21: 345-367.

Egyedi TM, Sherif MH (2010). Standards dynamics through an innovation lens: Next-generation Ethernet Networks. IEEE Commun. Magaz., pp. 166-171.

Eisenhardt KM, Graebner ME (2007). Theory building from cases: Opportunities and challenges. Acad. Manage. J., 50(1): 25-32. 
Elharidy AM, Nicholson B, Scapens RW (2008). Using grounded theory in interpretive management accounting research. Qual. Res. Account. Manage., 5(2): 139-155.

Fichman RG (2001). The role of aggregation in the measurement of ITrelated organizational innovation. MIS Q., 25(4): 427-455.

Forment MA, Guerrero MJC, González MAC, Peñalvo FJG, Severance C (2009). Interoperability for LMS: the missing piece to become the common place for e-learning innovation. Lecture Notes in Computer Science, Vol. 5736; Second World Summit on the Knowledge Society, WSKS 2009, Chania, Crete, Greece, September, Proceedings, pp 16-18.

Fritscher B, Pigneur $Y$ (2010). Supporting business model modelling: A compromise between creativity and constraints. Proceedings $8^{\text {th }}$ International Workshop on Task models and Diagrams, Springer, LNCS 5963: 28-43.

Gasser U, Palfrey J (2007). Breaking down digital barriers: When and how ICT interoperability drives innovation. Berkman Publication Series, November. Harvard University and the University of St. Gallen, sponsored by Microsoft.

Ghauri P, Gronhaug K (2005). Research methods in business studies A practical guide. $3^{\text {rd }}$ ed. Prentice Hall, UK.

Govindarajan V, Trimble C (2005). 10 rules for strategic innovators From idea to execution. Harvard Business School Press, Boston, MA, USA.

Hage JT (1999). Organizational innovation and organizational change. Ann. Rev. Sociol., 25: 597-622.

Hahn A (2004). Interoperability: A key to innovation. [Available at www.itaide.org accessed on 01-12-2010].

Hargadon A, Sutton RI (2000). Building an innovation factory. Harvard Business Review, May-June.

Huff AS, Jenkins M (2002). Mapping strategic knowledge. SAGE Publications Ltd., London, UK.

Hyvättinen H (2006). Interface standards and creating innovation markets - Implications on SMEs in a technology programme. Technovation, 26(2): 262-273.

lansiti M, Levien R (2004). The keystone advantage - What the new dynamics of business ecosystems mean for strategy, innovation, and sustainability. Harvard Business School Press, Boston, MA, USA.

lorio $P$ (2009). Interoperability in the city of Tampa: A partnership with the department of Homeland Security. In: Hakim S, Blackstone EA (Eds.), Safeguarding homeland security, Springer Science+Business Media, Pp. 233-239.

ISO CEN/ISO 11354 (2009). Requirements for establishing manufacturing enterprise process interoperability - Part 2: Maturity models for assessing enterprise interoperability. ( $2^{\text {nd }}$ December). V. 2.1

Izza S, Imache R, Vincent L, Lounis Y (2008). An approach for the evaluation of the agility in the context of Enterprise Interoperability. In: Mertins K, Ruggaber R, Popplewell K, Xu X (Eds.) Enterprise interoperability III - New challenges and industrial approaches. Springer-Verlag, London, UK, pp. 3-13.

Jashapara A (2004). Knowledge management - An integrated approach. Pearson Education Limited, UK.

Javidan M (2004). Performance orientation. In: House RJ, Hanges PJ, Javidan M, Dorfman PW, Gupta V (Eds). Culture, leadership and organizations: The GLOBE study of 62 societies. SAGE Publications Inc, California, USA, pp. 239-281.

Johansson F (2007). O Efeito Medici - O que nos podem ensinar os elefantes e as epidemias acerca da inovação. Casa das Letras, Portugal. Translation of the original The Medici Effect by Harvard Business School Press, Boston, MA, USA.

Kelley T, Littman J (2006). The ten faces of innovation - Strategies for heightening creativity. Profile Books Ltd., London, UK.

Kim WC, Mauborgne R (2005). Blue Ocean Strategy. How to create uncontested market space and make competition irrelevant. Harvard Business School Press, Boston, MA, USA.

Kimble C, Bourdon I (2008). Some success factors for the communal management of knowledge. Int. J. Inform. Manage., 28(6): 461-467.

Knothe T, Jochem R (2009). Interoperability issues in the field of innovation management. The International Conference on Interoperability for Enterprise Software and Applications, 20-23 April,
Beijing, China. IEEE Comput. Soc., pp. 15-19.

Kogut B (2000). The network as knowledge: Generative rules and the emergence of structure. Strat. Manage. J., 21: 405-425

Kotler P, Keller KL (2009). Marketing Management. $13^{\text {th }}$ ed. Pearson Education Inc., New Jersey, USA.

Krause $F$ (2011). The reflective entrepreneur - A dynamic learning perspective on the creation of entrepreneurial opportunities. Master's dissertation successfully submitted to the Faculty of Engineering, Mads Clausen Institute, SDU University of Southern Denmark, May.

Langley A (1999). Strategies for theorizing from process data. Acad. Manage. Rev., 24(4): 691-710.

Laurindo FJB (2002). Tecnologia da informação - Eficácia nas organizações. $2^{\text {nd }}$ ed. Editora Futura, São Paulo, Brazil.

Lee H-W (2010). Maximizing knowledge preservation and transformation in organization. Afr. J. Bus. Manage., 4: 3769-3774.

Lee H-W, Yu C-F (2010). Effect of relationship style on innovation performance. Afr. J. Bus. Manage., 4(9), 4: 1703-1708.

Li M-S (2008). Interoperability to drive open innovation of enterprises. Composition-Based Software Systems ( $7^{\text {th }}$ International Conference). IEEE Computer Society.

Li M-S, Cabral R, Doumeingts G, Popplewell K (Eds.) (2006). Enterprise Interoperability Research Roadmap. Final Version, $31^{\text {st }}$ July. European Commission.

Li M-S, Crave S, Grilo A, van den Berg R (Eds.) (2008). Value Proposition for Enterprise Interoperability. Final Version. $21^{\text {st }}$ January. European Commission.

Lilien GL, Morrison PD, Searls K, Sonnack M, von Hippel E (2002). Performance assessment of the lead-user idea-generation process for new product development. Manage. Sci., 48(8): 1042-1059.

Lopes M, Teixeira AC (2009). Open innovation in firms located in an intermediate technology developed country. FEP Working Paper №314, March, Faculdade de Economia, Universidade do Porto.

MacCormack A, Herman K (2004). Intel Research: Exploring the Future. Harvard Business School Case.

Malhotra A, Majchrzak A, Carman R, Lott V (2001). Radical innovation without collocation: A case study at Boeing-Rocketdyne. MIS Q., 25(2): 229-249.

Mansell R, Avgerou C, Quah D, Silverstone R (2007). The challenges of ICTs. In: Mansell R, Avgerou C, Quah D, Silverstone R (Eds.). The Oxford Handbook of Information and Communication Technologies, Oxford University Press, Oxford, UK, pp. 1-28.

Martin JA, Eisenhardt KM (2010). Rewiring: Cross-Business-Unit Collaborations in Multibusiness Organizations. Acad. Manage. J., 53(2): 265-301.

Mason J (2002). Qualitative researching. $2^{\text {nd }}$ ed. SAGE Publications Ltd., London, UK.

Mateus A (2006). Economia Portuguesa. Editorial Verbo, Portugal.

Mertins K, Ruggaber R, Popplewell K, Xu X (2008). Preface. In: Mertins K, Ruggaber R, Popplewell K, Xu X (Eds.), Enterprise interoperability III - New challenges and industrial approaches, Springer-Verlag, London, pp. 5-6.

Miettinen O, Mazhelis O, Luoma E (2010). Managerial growth challenges in small software firms: A multiple case study of growthoriented enterprises. In: Tyrvainen $\mathrm{P}$, Jansen $\mathrm{S}$, Cusumano MA (Eds.). Software Business - First International Conference - ICSOB, 2010 - Finland, June 2010 - Proceedings - LNBIP 51. SpringerVerlag, Berlin Heidelberg, pp. 26-37.

Miller P (2000). Interoperability: What is it and why should I want it? Ariadne, 24, [Available at http://www.ariadne.ac.uk/issue24/interoperability/ accessed on 17-022011].

Moore GA (2006). Dealing with Darwin - How great companies innovate at every phase of their evolution. Capstone (A Wiley Company), West Sussex, England.

Moreira AC (2011). Inovação: Conceitos e desafios. In: Dantas J, Moreira AC (eds.). O processo de inovação - Como potenciar a criatividade organizacional visando uma competitividade sustentável. Lidel - Edições Técnicas, Lda., Lisbon, Portugal, pp. 1-41.

Moreira AC, Carneiro LFM, Selada C (2008). Defining the regional innovation strategy for the year 2015: The case of the ITCE clusters in the North of Portugal. Int. J. Innov. Reg. Dev., 1(1): 66-89. 
Moreira AC, Carneiro LFM, Tavares MPT (2007). Critical Technologies for the North of Portugal in 2015: The case of ITCE sectors Information technologies, communication and electronics. Int. J. Foresight Innov. Pol., 3(2): 187-206.

Morgan JM, Liker, JK (2006). Sistema Toyota de desenvolvimento de produto - Integrando pessoas, processo e tecnologia. São Paulo, Brazil: ARTMED® EDITORA S.A. Translation of The Toyota product development process: Integrating people, process and technology.

Myers MD (1997). Qualitative Research in Information Systems. MISQ Discovery, archival version, June 1997 [Available at http://www.misq.org/discovery/MISQD_isworld/]. MISQ Discovery, updated version, last modified: October 1, 2009 [Available at www.qual.auckland.ac.nz accessed on 10-12-2009]. MIS Q., 21(2): 241-242.

North DC (2005). Understanding the process of economic change. Princeton University Press, Princeton, New Jersey, USA.

Oliveira MA, Ferreira JJP (2010a). Inspiring disruptive change: A novel approach to modelling the value creation process. A full paper presented orally and published in the International Conference IADIS e-Society 2010 Proceedings, March 18-21, Hotel Meliã Gaia Porto. pp 203-212.

Oliveira MA, Ferreira JJP (2010b). Modelling change using a novel business narrative modelling language. A paper presented and published on the Website of the $5^{\text {th }}$ Workshop on Organizational Change and Development: Core Competences in a Changing World, Vienna, Austria, pp. 23-24.

Oliveira MA, Ferreira JJP (2010c). Strategic change communication using a novel Business Narrative Modelling Language. A full paper presented virtually and published in the conference proceedings of the International Conference of Education, Research and Innovation ICERI2010 (organized by IATED). Madrid, Spain, pp. 15-17.

Oliveira MA, Ferreira JJP (2011a). Facilitating qualitative research in business studies - Using the business narrative to model value creation. Afr. J. Bus. Manage., 5(1): 4: 68-75.

Oliveira MA, Ferreira JJP (2011b). Book review - Business Model Generation: A handbook for visionaries, game changers and challengers. Afr. J. Bus. Manage., 5(7): 4.

Oliveira MA, Ferreira JJP (2011c). Producing innovation: Comments on Lee and Yu (2010). Afr. J. Mark. Manage., 3(3): 65-67.

Oliveira MA, Ferreira JJP (Forthcoming). A guide to the Business Narrative Modelling Language (BNML).

Osterwalder A, Pigneur $Y$ (2010). Business model generation. John Wiley and Sons, Inc., Hoboken, New Jersey, USA.

Patterson DA, Hennessy JL (1994). Computer organization and design: The hardware / software interface. Morgan Kaufmann Publishers, California, USA.

Pavlou P (2004). IT-Enabled competitive advantage: The strategic role of IT on dynamic capabilities in collaborative product development partnerships. Ph.D. dissertation summary. Marshall School of Business, University of Southern California.

Pecujlija M, Nerandzic B, Perovic V, Jevtic A, Simic N (2010). Initiating innovation in Serbian companies' organizational cultures. Afr. J. Bus. Manage., 4(18): 3957-3967.

Peat M (2009). Data + Information Systems = Financial Innovation. In: Kundisch D et al. (Eds.), Enterprise Applications and Services in the Finance Industry, LNBIP, Springer-Verlag Berlin Heidelberg, 23(1): 110.

Pereira AT (2011). Internacionalização - Tecnológicas Portuguesas também vão à Alemanha para combater a crise. Jornal de Negócios, pp. 16-17. 3rd March.

Pisano GP, Verganti R (2008). Which Kind of Collaboration is Right for You? Harv. Bus. Rev., pp. 78-86.

Pollard D (2005). Will That Be Coordination, Cooperation, or Collaboration? [Available at: http://blogs.salon.com/0002007/categories/businessInnovation/2005/ 03/25.html\#a1090 on 28-11-2010].

Porter ME (1980). Competitive strategy - Techniques for analyzing industries and competitors. Free Press, New York, NY, USA.

Porter ME (1990). The Competitive Advantage of Nations. Free Press, New York, USA.

Porter ME, Schwab K, Sala-i-Martin X, Lopez-Claros A (2004). The
Global Competitiveness Report 2003-2004, World Economic Forum, Geneva, Switzerland.

Rabelo RJ (2008). Advanced collaborative business ICT infrastructures. In: Camarinha-Matos LM, Afsarmanesh H, Ollus M (Eds.), Methods and tools for collaborative networked organizations. Springer, New York, NY, USA, pp. 337-370.

Rabelo RJ, Castro MM, Conconi A, Sesana M (2008). The ECOLEAD Plug and Play collaborative business infrastructure. In: CamarinhaMatos LM, Afsarmanesh $\mathrm{H}$, Ollus M (Eds.), Methods and tools for collaborative networked organizations. Springer, New York, NY, USA, pp. 371-394.

Raus M, Liu J, Kipp A (2010). Evaluating IT innovations in a businessto-government context: A framework and its applications. Govern. Inform. Q., 27: 122-133.

Reding V (2008). Foreward. In: Li M-S, Crave S, Grilo A, van den Berg $R$ (Eds.), Value Proposition for Enterprise Interoperability. Final Version, European Commission, p. 1.21 $1^{\mathrm{st}}$ January.

Remenyi D, Williams B, Money A, Swartz E (1998). Doing research in business and management - An introduction to process and method. SAGE Publications Ltd., London, UK.

Ronkko M, Peltonen J (2010). Internationalization of software firms. In: Tyrvainen P, Jansen S, Cusumano MA (Eds.), Software Business First International Conference - ICSOB, 2010 - Finland, June 2010 Proceedings - LNBIP 51, Springer-Verlag, Berlin Heidelberg, pp. 3848.

Rosenberg N (1990). Why do firms do basic research (with their own money?). Res. Pol., 19(2): 165-174.

Saur-Amaral I (2010). Revisão sistemática da literatura com EndNote X1 e NVivo 8 - Uma abordagem simples e eficaz para investigadores da área das ciências sociais. GOVCOPP, DEGEI/SACJSP - UA, Linha de Competitividade.

Scapens RW (2007). Qualitative analysis and case study research lecture notes. Management Science PhD Program, Faculty of Economics, University of Porto, Portugal.

Schein EH (1992). Organizational culture and leadership. $2^{\text {nd }}$ ed. Jossey-Bass, San Francisco, CA, USA.

Schwab K (Ed.) (2010). The Global Competitiveness Report 2010-2011. World Economic Forum, Geneva, Switzerland.

Serrano V, Fischer T (2007). Collaborative innovation in ubiquitous systems. J. Intel. Manuf., 18(5): 599-615.

Siggelkow N (2007). Persuasion with case studies. Acad. Manage. J., 50(1): 20-24.

Silverstein A, Schomberg R (2007). Highlighting interoperability - How to design a new metering-system architecture. Public Utilities Fortnightly, pp. 78-82.

Soto-Acosta P, Loukis E, Colomo-Palacios R, Lytras MD (2010). An empirical research of the effect of internet-based innovation on business value. Afr. J. Bus. Manage., 4(18): 4096-4105.

Teixeira AC, Tavares-Lehmann AT (2007). Investimento directo estrangeiro, capital humano e inovação: Uma aplicação ao caso Português. Vida Económica, Portugal.

Tidd J, Bessant J, Pavitt K (2005). Managing innovation - Integrating technological, market and organizational change. $3^{\text {rd }}$ ed. John Wiley \& Sons Ltd., West Sussex, England.

Triandis HC (2004). Foreward. In: House RJ, Hanges PJ, Javidan M, Dorfman PW, Gupta V (Eds). Culture, leadership and organizations: The GLOBE study of 62 societies. SAGE Publications Inc, California, USA, pp. 15-19.

Tsilas NL (2007). Enabling open innovation and interoperability: Recommendations for policy-makers. Proceedings of the $1^{\text {st }}$ International Conference on theory and practice of electronic governance. ICEGOV, December 10-13, Macao, pp. 53-56.

Tzeng $\mathrm{CH}$ (2009). A review of contemporary innovation literature: A Schumpeterian perspective. Innov. Manage. Pol. Pract., 11(3): 373394.

Unicist ontologies of human learning and innovation (2012). The Unicist Research Institute. [Available at http://www.unicist.org/index.php, accessed on 15-03-2012].

Uschold M, King M, Moralee S, Zorgios Y (1998). The enterprise ontology. Knowl. Eng. Rev., 13(1): 31-89.

Usunier J-C, Lee JA (2005). Marketing across cultures. $4^{\text {th }}$ ed. Pearson 
Education Limited, Harlow, Essex, England.

Valtakoski A, Ronkko M (2010). Diversity of business models in software industry. In: Tyrvainen P, Jansen S, Cusumano MA (Eds.), Software Business - First International Conference - ICSOB, 2010 Finland, June 2010 - Proceedings - LNBIP 51, Springer-Verlag Berlin Heidelberg, pp. 1-12.

van Assen M, van den Berg G, Pietersma P (2009). Key management models - The $60+$ models every manager needs to know. $2^{\text {nd }}$ ed. Pearson Education Limited, Harlow, UK.

von Hippel E, Thomke SH, Sonnack M (1999). Creating breakthroughs at 3M. Harv. Bus. Rev., 77(5): 47-57.

Webster J, Watson RT (2002). Analyzing the past to prepare for the future: Writing a literature review. Guest editorial. MIS Q., 26(2): 1323.
Weerawardena J, Mort GS (2006). Investigating social entrepreneurship: A multidimensional model. J. World Bus., 41: 2135.

Winston BE (2010). The place for qualitative research methods in the study of servant leadership. In: Dierendonck D, Patterson K (Eds.), Servant Leadership - Developments in theory and research. Palgrave Macmillan, Hampshire, UK, pp. 180-191.

Woodside AG (2010). Case study research: Theory, methods and practice. Emerald Group Publishing Ltd., UK.

Yin RK (2003). Case study research - Design and methods. $3^{\text {rd }}$ ed. SAGE Publications Inc., California, USA. 